\title{
Perception and Recollection of Fire Hazards in Dwelling Fires
}

Lynn M. Hulse ${ }^{a *}$, Edwin R. Galea ${ }^{a}$, Owain F. Thompson ${ }^{b}$, David Wales ${ }^{b}$

a Fire Safety Engineering Group, Faculty of Liberal Arts \& Sciences, University of Greenwich, Old Royal Naval College, Park Row, London SE10 9LS, UK

${ }^{\mathrm{b}}$ Kent Fire \& Rescue Service, Headquarters, The Godlands, Straw Mill Hill, Tovil, Maidstone ME15 6XB, UK

*Corresponding author's email address: L.Hulse@greenwich.ac.uk

Co-authors' email addresses: E.R.Galea@greenwich.ac.uk, Owain.Thompson@kent.fire-uk.org, david.wales@nationalfirechiefs.org.uk

\section{Acknowledgements}

This work was supported by Innovate UK and the EPSRC as part of a Knowledge Transfer Partnership between Kent Fire \& Rescue Service and the University of Greenwich (KTP number 9153) and the LIFEBID (Lessons In Fire \& Evacuation Behaviour In Dwellings) project (see Wales et al., 2015). The authors are listed in descending order of contribution to the production of this paper. They thank the Defence Fire Training and Development Centre at Manston for providing facilities in which to film mock fires. The authors are also grateful to their FSEG colleague Asim Siddiqui for technical support when creating and running the online experiments.

Declarations of interest: none 


\section{Highlights:}

1. Flame height and smoke volume poorly recollected under free recall conditions

2. Recollection of hazard size improved by use of layperson-friendly descriptors

3. Recollection performance impacted by hazard size but not by delayed testing

4. Willingness to engage with fire hazards moderated by perceived hazard size

5. Yet willingness still worryingly high; gender and prior fire experience play roles 


\section{Abstract}

Current understanding of dwelling fire injury outcomes is impacted by data limitations, confounds, and failures to adequately examine occupant behaviour. For instance, research rarely considers: occupant perception of fire hazard properties (e.g. size of flames/smoke when first encountered); resultant engagement (enter smoky room, tackle flames); whether hazard size percepts are accurate when recollected for investigators; and what the best recollection method is. Two experiments $(N=141,132)$ presented short videos of kitchen fires where hazard size was either Small, Mid or Large. Immediately after seeing this (Experiment 1), or after a delay (Experiment 2), participants' performance at recollecting hazard size and their willingness to (hypothetically) engage with the hazards was tested. Recollection performance was compared across three methods. Interestingly, free recall resulted in poor performance but performance improved by 2-3 times when using two types of layperson-friendly descriptors (text, pictures) that allowed hazard size to be referenced to other scene elements. Pictures had a slight advantage over text descriptors. Larger hazards were recollected less accurately than small ones, albeit still somewhat meaningfully; the exception was mid-sized smoke and attentional narrowing effects are discussed. Importantly, while increased hazard size reduced willingness, a concerning percentage of participants nevertheless considered engaging with the largest hazards; such risky behaviours may explain injury outcomes. Prior fire experience and gender affected recollection and willingness, often interacting with hazard size. Delayed recollection and individual differences did not. These findings suggest occupant behaviour, characteristics and hazard size data need capturing to help assess fire injury risks.

Keywords: Dwelling fire; Flame; Smoke; Perception; Memory; Risk 


\section{Introduction}

For the UK and many other parts of the world, dwelling fires are the leading source of all fire-related fatal and non-fatal injuries, not to mention the cause of significant property damage and psychological distress (Home Office, 2018; Kobes and Groenewegen, 2009; Lollar, 2010; Scottish Fire and Rescue Service, 2018; U.S. Fire Administration, 2019). Despite this, for several decades now, dwelling fires and particularly human behaviour during dwelling fires have received a disproportionately small amount of attention from the research community. What research has been conducted has tended to focus on fatal dwelling fire injuries, understandably, and results have converged suggesting fatalities are more likely when occupants are unaware of the fire and/or less capable of removing themselves from harm's way (e.g. asleep, medically impaired, intoxicated) (Brennan, 1999; Harpur et al., 2014; Holborn et al., 2003; Miller, 2005; Runyan et al., 1992). The picture for non-fatal injuries is less clear; it is more difficult to identify and/or access such cases and, when they are sampled, they may only include burn injuries, cases treated at hospital, or be combined with either dwelling fire fatalities or non-fatal injuries occurring from other types of fires (DiGuiseppi et al., 2000; Haikonen et al., 2013; Hasofer and Thomas, 2006; Warda et al., 1999).

Despite these multiple data limitations and confounds, two dwelling fire studies were found that potentially offer insight into human behaviour and non-fatal injuries. A qualitative study (Thompson and Wales, 2015) focusing solely on injured occupants who survived noted that, out of their 10 interviewees, most were injured while attempting to tackle the fire. An earlier study (Hall Jr., 2004), using data from a national fire incident database, was able to distinguish occupants recorded as attempting rescue/firefighting activities into non-fatally injured $(n=22)$ and uninjured ( $n$ $=15)$. It reported that these activities typically ended when the occupant had been forced out of the fire zone (non-fatally injured), or had succeeded in their activity and/or avoided the fire zone altogether (uninjured). So, it might be the case that non-fatal injuries tend to occur through occupant action rather than inaction, as well as through failing to perceive risk or willingly taking risks around fire. Nevertheless, this speculation is based on very small samples at present. Thus, 
there is a clear need for further research to collect detailed first-hand data on occupant behaviours during dwelling fires and analyse relationships between those behaviours and injury status. However, first, it is necessary to examine how well people perceive and recollect fire hazards (flames, smoke): if people struggle to recall sufficient, accurate details about these hazards, then any assessment of risks faced during dwelling fires and subsequent behavioural responses will prove difficult. This is the focus of the current paper.

To the authors' knowledge, no study to date has systematically examined occupant perception and recollection of fire hazards. This is surprising, given how useful accurate descriptions of, say, flame height or smoke volume could be for fire and insurance investigators, and coroners' officers, as well as how it could help increase fire safety professionals' understanding of how fires result in certain outcomes, and whether any behaviours involved in that need challenging, assisting or promoting. Research findings from outside of the field of fire safety raise questions over whether occupants can correctly perceive and recollect hazard size. Harber et al. (2011) found that visual perception of spatial properties such as height can be distorted when a situation is threatening, especially when confidence in one's own abilities is depleted (in this case, participants with different levels of self-esteem were asked to look several storeys down a stairwell and perceive how high off the ground they were but prevented from holding onto a protective handrail while doing so). Other research, on eyewitness testimony, has reported that memory for threatening scenes may become spatially focused, with the stimulus depicting danger (e.g. scene showing the gruesome outcome of a knife attack) being recalled in "close up" (Safer et al., 1998). Thus, if occupants experiencing a dwelling fire were to encounter a greater threat, one likely beyond their control, e.g. taller flames or a larger volume of smoke, would their perception and subsequent recollection of hazard size be accurate?

An additional question is how willing occupants would be to approach and engage with fire hazards, given their size. Such risk-taking around taller flames or a greater volume of smoke, combined with an accurate recollection of hazard size, would indicate a disregard or acceptance of 
the risk faced rather than poor risk perception. A series of experiments (Jin, 2002) demonstrated that some participants were willing to move through a corridor or remain in a room filled with smoke - of varying densities, irritancy levels and/or heat levels - even to the point where they found it difficult to open their eyes or walk straight. A gender difference was noticed in one experiment, with females appearing more psychologically sensitive to a reduction in visibility than males. However, these experiments were designed with the aim of drawing conclusions about evacuation behaviour, i.e. movement through smoke in order to escape to a place of safety, rather than a deliberate approach towards the source of the fire. Moreover, the smoke's properties were measured by researchers, in scientific terms (e.g. extinction coefficient in $1 / \mathrm{m}$ ); for those collecting accounts from dwelling fire survivors, such metrics are unsuitable and a different method is required to capture hazard properties in a way that is more "layperson-friendly" and can be compared meaningfully across cases. Two studies of real building fires in the 1970s and 80s (Canter, 1996; Wood, 1972) reported a willingness from occupants to move through smoke and (especially if male) tackle the fire. However, Canter did not report any measure of the perceived size of the fire hazards during these encounters. Wood did report how occupants perceived the fire (in terms of its seriousness) when they first became aware of it but unfortunately the measure, while laypersonfriendly, precludes objective judgement (i.e. Not At All/Quite/Extremely Serious). Wood's sample also included a large percentage of buildings that were not dwellings.

The current study aimed to address these issues by investigating the following: people's perception of fire hazards (specifically the size of flames/smoke) when they first see them in a dwelling fire context; resultant (hypothetical) engagement with the hazards (i.e. willingness to enter the smoky room, attempt to extinguish the flames); whether hazard size percepts are accurate when recollected; and what the best recollection method is. Two experiments were designed where participants witnessed short videos depicting a dwelling fire, one with visible flames and the other with visible smoke. The size of these hazards was manipulated so participants either saw them when small or larger. Immediately after seeing the videos (Experiment 1), or after a delay (Experiment 2), 
participants' performance at recollecting hazard size and their willingness to engage with the hazards was tested. Recollection performance was compared across three methods, one common (free recall) and two novel. The novel methods involved the use of newly created text and picture descriptors, which were designed to capture hazard size in a more layperson-friendly yet objectively meaningful way by allowing participants to reference the hazards to other elements (their own body, the walls and ceiling of the room of fire origin). Data on occupant characteristics were collected also to explore if they had an effect on recollection performance and willingness, independent of or interacting with hazard size.

\section{Materials and Methods: Experiment 1}

\subsection{Participants}

Before recruitment began for these experiments, ethical approval was sought and received from the involved university's research ethics committee (UREC). Following that, a total of 1,186 subscribers to a GovDelivery.com list were invited by email to take part in an online survey measuring their perception of "certain [life] events, behaviours and attitudes to those events". No explicit mention of fires or experiments was made in order to avoid priming participants for what they would be presented with. However, sufficient other task details and an opportunity to request further information was provided at the outset so that participants could give their informed consent (which they did via ticking the relevant boxes on the start page of the survey). Participants were encouraged to notify (adult, 18+) friends and family about the study. No financial incentives were offered for participation. In response to this invite, 318 survey links were clicked on and 158 surveys completed. Of the 158, 17 were excluded from analysis due to being completed after the survey deadline, leaving a final sample of 141 participants. Overall, the gender ratio was $55 \%$ male to $45 \%$ female. Ages ranged from 22 to 89 years old $(M=60.18$ years, $S D=12.69)$. All participants resided in the UK and 96\% identified as belonging to a White UK ethnic group. Regarding education, $41 \%$ were educated to secondary level, $36 \%$ to undergraduate level, and $23 \%$ to postgraduate level. Almost all participants (99\%) declared they had gained fire safety knowledge from at least one 
source (typically the workplace, $66 \%$ ) and $53 \%$ had personally experienced a fire in the past. However, few (7\%) worked in areas related to fire/fire safety. Finally, $71 \%$ of participants reported having visual impairments, although these were frequently (88\%) of a type that could be corrected with lenses, and participants were reminded to wear corrective lenses if appropriate.

\subsection{Design, materials and procedure}

A mixed design was employed, meaning that for one part of the experiment (i.e. watching the video clips) participants were randomly assigned by the researchers into groups, with each group seeing something that differed in one important respect - this was the "experimental manipulation" - while for the other parts of the experiment there was no division of participants (i.e. they all witnessed two clips in total showing fire hazards, they all were asked to provide recollections of the hazards using each of the three methods on offer, and they all provided answers about their willingness to engage with the hazards).

Three sets of video clips were created showing a mock dwelling fire in a kitchen. Each set comprised two clips: one showing the kitchen fire where the visible hazard was flames and one showing the kitchen fire where the visible hazard was smoke. The reason for depicting these two fire hazards separately was because:

(a) dwelling fires can take these different forms, i.e. "fast-flaming fires" (where something flammable flares quickly, igniting other items nearby and producing smoke in lower quantities initially, meaning that flames are more visible then) vs. "smouldering fires" (where combustion occurs more slowly, producing only smoke from the ignited item [albeit often reaching large quantities] unless or until the conditions reach the critical point for the fire to change into a fastflaming fire); and

(b) accordingly, there can be different consequences for occupants (e.g. in terms of how they perceive and respond to the fire, as well as in terms of the risk, type and severity of injury). 
The sets of video clips differed from each other with respect to the size of the hazards shown in them. As can be seen in Fig. 1, the Small set displayed each fire hazard early in its development (i.e. small flames moving just beyond the top of the item of ignition, puffs of smoke emitting from the item of ignition), the Mid set displayed them more developed (i.e. flames reaching halfway up the wall from the countertop, a smoke layer forming at the ceiling), while the Large set displayed them at a further stage of development (i.e. tall flames reaching and running across the ceiling, a distinct smoke layer descending from the ceiling to below head height). The experiment began with participants unwittingly being assigned to a group that would see only one of the three sets (Small $n=47$, Mid $n=47$, Large $n=47$ ). Hazard clips were shown sequentially in each set. As the aim was to investigate participants' immediate perception of a fire, clips lasted for just two seconds.

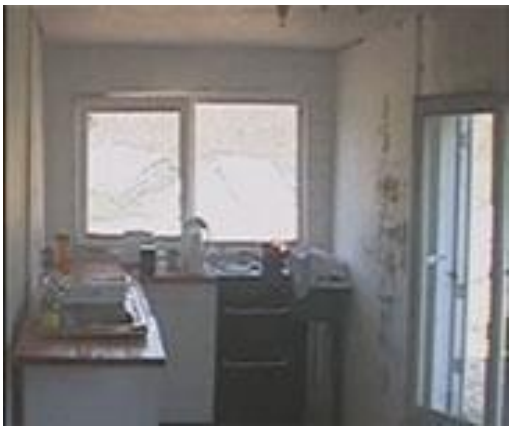

(a)

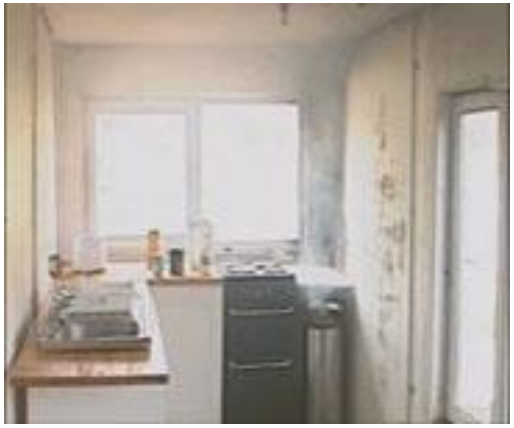

(b)

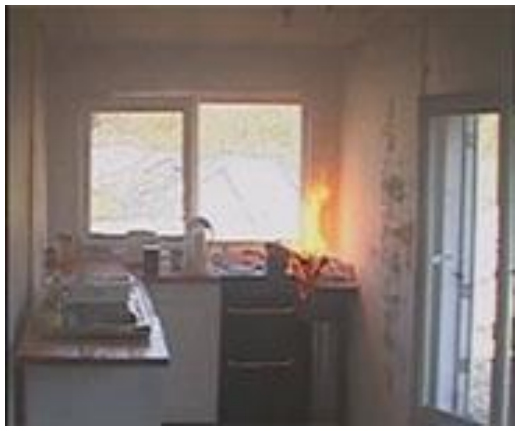

(c)

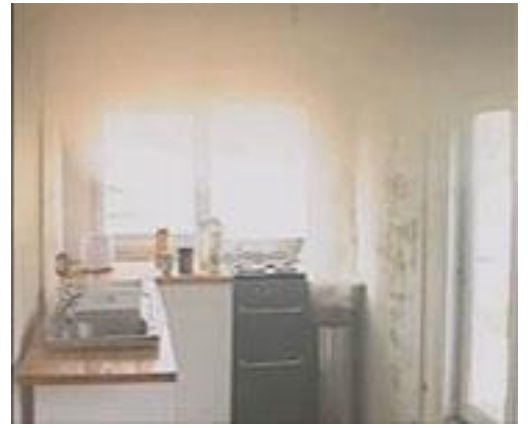

(d)

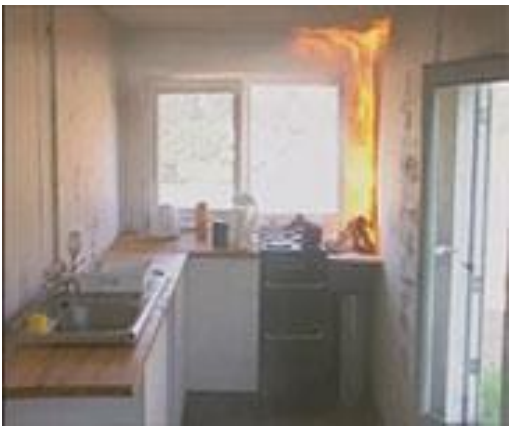

(e)

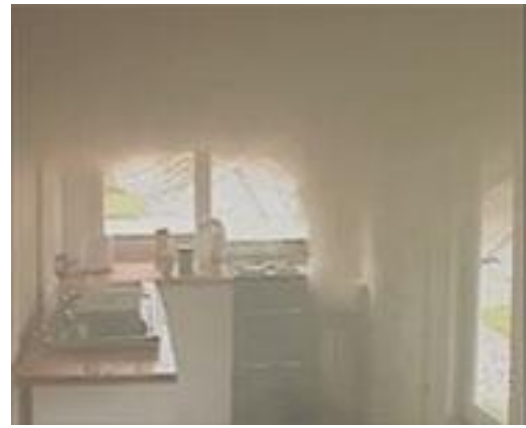

(f)

Fig.1. Stills from the Small $(a, b)$ Mid (c, d) and Large $(e, f)$ flame and smoke video clips respectively

Immediately after seeing both clips, participants were asked to recollect the fire hazards, first via free recall, then using text descriptors, and finally using picture descriptors, all designed to be layperson-friendly. The free recall test asked participants to "Describe, in as much detail as possible, what you saw, e.g. the layout of the room, what objects were present, what the 
flames/smoke looked like, etc.". They were asked to describe the flame and smoke scenes separately. The text descriptor test involved participants selecting one descriptor, from a choice of five, which best described the flames and smoke seen, respectively (Table 1). The last test involved selecting one picture descriptor, again from a choice of five, that best depicted the flames and smoke seen, respectively (note, unlike in Table 1, text and picture descriptors were not displayed together during the experiment but separately).

Table 1. Text and picture descriptors for each fire hazard

\begin{tabular}{|c|c|c|c|c|c|}
\hline Flame & A & B & C & D & $\mathbf{E}$ \\
\hline Text & $\begin{array}{l}\text { The height of } \\
\text { the flames was } \\
\text { about the size } \\
\text { of a hand }\end{array}$ & $\begin{array}{l}\text { The height of } \\
\text { the flames was } \\
\text { about the } \\
\text { length of an arm }\end{array}$ & $\begin{array}{l}\text { The height of } \\
\text { the flames was } \\
\text { about as tall as } \\
\text { an adult person }\end{array}$ & $\begin{array}{l}\text { The height of } \\
\text { the flames } \\
\text { meant they just } \\
\text { reached the } \\
\text { ceiling }\end{array}$ & $\begin{array}{l}\text { The height of } \\
\text { the flames } \\
\text { meant they } \\
\text { were running } \\
\text { along the } \\
\text { ceiling }\end{array}$ \\
\hline \multicolumn{6}{|l|}{ Picture } \\
\hline Smoke & \multicolumn{5}{|c|}{ A $\quad$ B } \\
\hline Text & $\begin{array}{l}\text { There were } \\
\text { puffs of smoke } \\
\text { coming from } \\
\text { the item that } \\
\text { was burning }\end{array}$ & $\begin{array}{l}\text { The smoke had } \\
\text { formed a thin } \\
\text { layer up at the } \\
\text { ceiling, but well } \\
\text { above head } \\
\text { height }\end{array}$ & $\begin{array}{l}\text { The smoke had } \\
\text { formed a thick } \\
\text { layer under the } \\
\text { ceiling, down to } \\
\text { just above head } \\
\text { height }\end{array}$ & \multirow[t]{2}{*}{$\begin{array}{l}\text { The smoke had } \\
\text { formed a deep } \\
\text { layer under the } \\
\text { ceiling, down to } \\
\text { around shoulder } \\
\text { level }\end{array}$} & $\begin{array}{l}\text { The room was } \\
\text { full of smoke }\end{array}$ \\
\hline Picture & & & & & \\
\hline & & 0 & 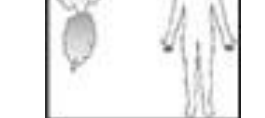 & 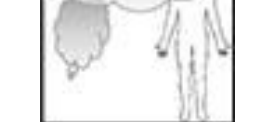 & \\
\hline
\end{tabular}

Two questions were posed after the recollection tests to measure willingness to engage with the hazards: (i) did participants believe they could have safely extinguished the flames, and (ii) would they have entered the room given the amount of smoke in it? Answers were provided using a 5point Likert-type scale, where $1=$ Strongly Disagree, $2=$ Disagree, $3=$ Not Sure, $4=$ Agree, and $5=$ Strongly Agree. Socio-demographic questions came last. The end page of the survey thanked the participants for their time and effort, and also provided a debrief explaining the nature of the study, 
including the experimental manipulation, and research questions that this study aimed to address. The median time taken to complete the entire experiment was nine minutes (IQR $=7-12)$.

\subsection{Data analysis}

The responses on the free recall and descriptors tests were analysed for recollection performance. Good performance was reflected by providing a description of hazard size, and being accurate in that description, as the provision of accurate details would assist investigators in a real incident. In contrast, failing to provide a description or providing a description that was not accurate would reflect poor performance, as this would be unhelpful to investigators.

Free recall answers were analysed in several stages. They were scored for the following key details: (a) room of fire origin (kitchen), (b) item of ignition (pot on stove/tea towel for flames, bin for smoke), and (c) hazard size (flame height, smoke volume), with (a) and (b) included to offer additional perspective on recollection performance. These details were coded first as $0=N o t$ Reported or $1=$ Reported and then, for those that were reported, coded as $0=$ Not Accurate or $1=$ Accurate. To be accepted as Reported and Accurate, there had to respectively be an attempt at description and it had to provide sufficient detail to allow a judgement about accuracy to be made by a fire safety professional (e.g. for item of ignition in the flames clip, "electrical appliance" was accepted as Reported but not as Accurate due to being too vague while "something on the stove/cooker/hob" was accepted as both Reported and Accurate. Likewise for hazard size, descriptions such as "high" [flames] and "lots" [smoke] were accepted as Reported but not Accurate for both the Mid and Large conditions since they were too vague but descriptions such as "20 inches" [Mid flames], "up to the ceiling" [Large flames], "smoke layer beginning to form at top part of room" [Mid smoke], and "thick smoke spreading around ceiling and walls" [Large smoke] were accepted as both Reported and Accurate). To ascertain the frequency of good recollection performance on the free recall test, the number of participants whose answers were coded as both Reported and Accurate was divided by the total number of participants and then multiplied by 100 . 
On the text and picture descriptor tests, all participants made a selection, thus all "reported" hazard size, and so answers were coded in a single stage as $0=$ Not Accurate or $1=$ Accurate. To be accepted as Accurate, participants had to select the correct descriptor. The correct descriptor for each hazard size, and general comprehension and usage of the descriptors, was determined via pilot testing with two samples (one sample included participants who were able to go back and view the videos multiple times for as long as they wanted before submitting their description of the hazards, while the other sample comprised occupants with actual experience of a dwelling fire who were able, during face-to-face testing in their homes, to supplement the descriptions of the hazards encountered in those fires by physically pointing out their seat and highest point reached). To ascertain the frequency of good recollection performance on the descriptor tests, the number of participants whose answers were coded as Accurate was divided by the total number of participants and then multiplied by 100 .

As mentioned in section 2.2, willingness to engage with the hazards was measured via rating scales. During analysis, the rating categories were merged from five down into three: dissenting answers (Strongly Disagree and Disagree) were re-coded as $1=$ No, Not Sure answers $=2$, and affirmative answers (Agree and Strongly Agree) re-coded as $3=$ Yes.

IBM SPSS Statistics v.20 was used to run descriptive statistics and inferential statistical tests. Effect sizes were also calculated: odds ratio (OR), Cohen's $d$, and the correlation coefficients Pearson's $r$ and Spearman's rho (see, for example, lalongo, 2016). ORs range from 0.00 to infinity. An OR below 1.00 means a lowering of odds of an outcome occurring when certain circumstances are present, as opposed to absent, while an OR above 1.00 means an increase in odds; the further away from 1.00 the $O R$ is, the greater the lowering/increasing effect. Cohen's $d$ ranges from 0.00 to infinity, while $r$ and rho both range from 0.00 to -1.00 or 1.00 . The further away from 0.00 the value is, the greater the difference between a variable's categories as measured on some outcome (for d) 
or the greater the (negative or positive) association between variables (for $r$ and rho). An alpha level of .05 was the cut-off for statistical significance.

\section{Results: Experiment 1}

\subsection{Recollection performance: comparison of three methods}

Using free recall, the room of fire origin was reported most frequently (flame clip $80 \%$, smoke clip 72\%) and with complete accuracy each time (flame, smoke clips $100 \%$ ). The item of ignition was reported less frequently, albeit still by the majority of participants (flame clip 66\%, smoke clip 55\%), and accuracy was good (flame clip 94\%, smoke clip 81\%). In contrast, hazard size was reported by less than a third of the sample (flame clip 31\%, smoke clip $29 \%$ ) and accuracy was also lower, especially for the smoke (flame clip 84\%, smoke clip 66\%). This meant recollection performance using free recall was often poor (Table 2). When compared to recollection performance using text and picture descriptors, it was found that the frequency of good performance was improved when using descriptors to describe hazard size. Performance on the two descriptor tests was similar, although the pictures appeared to have a slight advantage.

Table 2. Frequency of good recollection performance, overall, across test methods and hazard

\begin{tabular}{lccc}
\hline Hazard & Free Recall & Text Descriptors & Picture Descriptors \\
\hline Flame Height & $26 \%$ & $65 \%$ & $69 \%$ \\
Smoke Volume & $19 \%$ & $44 \%$ & $46 \%$ \\
\hline
\end{tabular}

\subsection{Recollection performance using descriptors: effect of experimental manipulation}

The experimental manipulation of hazard size appeared to affect recollection performance. When performance using the descriptors - or rather one aspect of performance, accuracy - was broken down according to the size of the hazard shown in the video clips (Table 3), it was noted that more than three-quarters of participants in the Small group were able to describe flame height and 
smoke volume accurately; this applied when the descriptor was text and when a picture. However, accuracy declined in the other groups, for both types of descriptor. Flame height accuracy was worst in the Large group, while smoke volume accuracy was particularly poor in the Mid group.

Table 3. Flame and smoke descriptor selection according to hazard size (correct answer)

\section{Text Descriptors}

\section{Picture Descriptors}

$\begin{array}{lllllllll}\text { A } & \text { B } & \text { C } & \text { D } & \text { E } & \text { A } & \text { B } & \text { C } & \text { D }\end{array}$

\begin{tabular}{|c|c|c|c|c|c|c|c|c|c|c|}
\hline \multicolumn{11}{|l|}{ Flame } \\
\hline Small & $\underline{87 \%}$ & $13 \%$ & - & - & - & $\underline{85 \%}$ & $15 \%$ & - & - & - \\
\hline Mid & $13 \%$ & $\underline{75 \%}$ & $6 \%$ & $6 \%$ & - & $11 \%$ & $\underline{79 \%}$ & $9 \%$ & $2 \%$ & - \\
\hline Large & $2 \%$ & $9 \%$ & $11 \%$ & $45 \%$ & $\underline{34 \%}$ & - & $11 \%$ & $30 \%$ & $17 \%$ & $43 \%$ \\
\hline \multicolumn{11}{|c|}{ Smoke } \\
\hline Small & $\underline{77 \%}$ & $19 \%$ & $4 \%$ & - & - & $\underline{81 \%}$ & $19 \%$ & - & - & - \\
\hline Mid & $32 \%$ & $30 \%$ & $\underline{17 \%}$ & $19 \%$ & $2 \%$ & $36 \%$ & $28 \%$ & $\underline{17 \%}$ & $19 \%$ & - \\
\hline Large & - & $9 \%$ & $40 \%$ & $\underline{38 \%}$ & $13 \%$ & $4 \%$ & $2 \%$ & $30 \%$ & $40 \%$ & $23 \%$ \\
\hline
\end{tabular}

\subsection{Recollection performance using descriptors: additional socio-demographic effects}

To test whether other factors, those related to the occupant, might further affect recollection performance when using the descriptors, logistic regression was employed. Logistic regression goes beyond testing whether one variable is significantly associated with another; it allows a model comprising several potentially relevant variables to be tested to see if they significantly predict an outcome of interest. Moreover, it can reveal the direction and relative magnitude of the effect each variable has (if any) on the outcome, while controlling for the other variables. Sometimes, the effect of a variable is dependent on another variable in the model, i.e. the two variables significantly interact with one another. For example, a variable might appear to have no significant effect until the effect of another variable reveals that, in combination, it does. Alternatively, a variable might have a significant effect in isolation but, in combination with another 
variable, the effect is changed in some way. If such interactions are expected, then interaction terms can also be added to the model to be tested with logistic regression.

In this analysis, the outcome of interest was binary - i.e. good, as opposed to poor, recollection performance - and so the specific type of test was binary logistic regression. Four tests were run, two to examine performance using the text descriptors (first to describe flame height, then to describe smoke volume) and two to examine performance using the picture descriptors (again, for describing flame height and then smoke volume). On every test, the model was a single block of the same variables (called predictor variables), which included socio-demographic characteristics (Age, measured continuously in years; Education, coded into three categories Secondary, Undergraduate, Postgraduate; Gender, coded into two categories - Male, Female; and Prior Fire Experience, coded into two categories - Yes, No) along with the experimental manipulation (Hazard Size, coded into three categories - Small, Mid, Large). To check if the sociodemographic variables interacted with the experimental manipulation, interaction terms (Age*Hazard Size, Education*Hazard Size, Gender*Hazard Size, Prior Fire Experience*Hazard Size) were initially added in a second block but are not reported further because their inclusion did not significantly improve the model (none of the interaction terms were found to significantly predict the outcome).

Descriptive statistics and more detailed output from the logistic regression tests are available in Appendix A and B, respectively. A summary of the test results is shown here in Fig. 2. Hazard Size was consistently found to be a significant predictor of good recollection performance, regardless of the type of descriptor being used (Smoke Text and Picture Descriptors - Mid [vs. Small]-sized hazards: all ps <.001, all ORs < 0.08; All Descriptors - Large [vs. Small]-sized hazards: all ps <.005, all ORs $<0.26$ ). Occupant characteristics had little effect on recollection performance; Education was the only other variable in the model found to be a significant predictor, and this was restricted to when participants were using text descriptors (Flame Text Descriptor - Undergraduate 
[vs. Secondary] level of education: $p=.031, \mathrm{OR}=0.34$; Smoke Text Descriptor - Postgraduate [vs. Secondary] level of education: $p=.010, O R=4.40$ ).

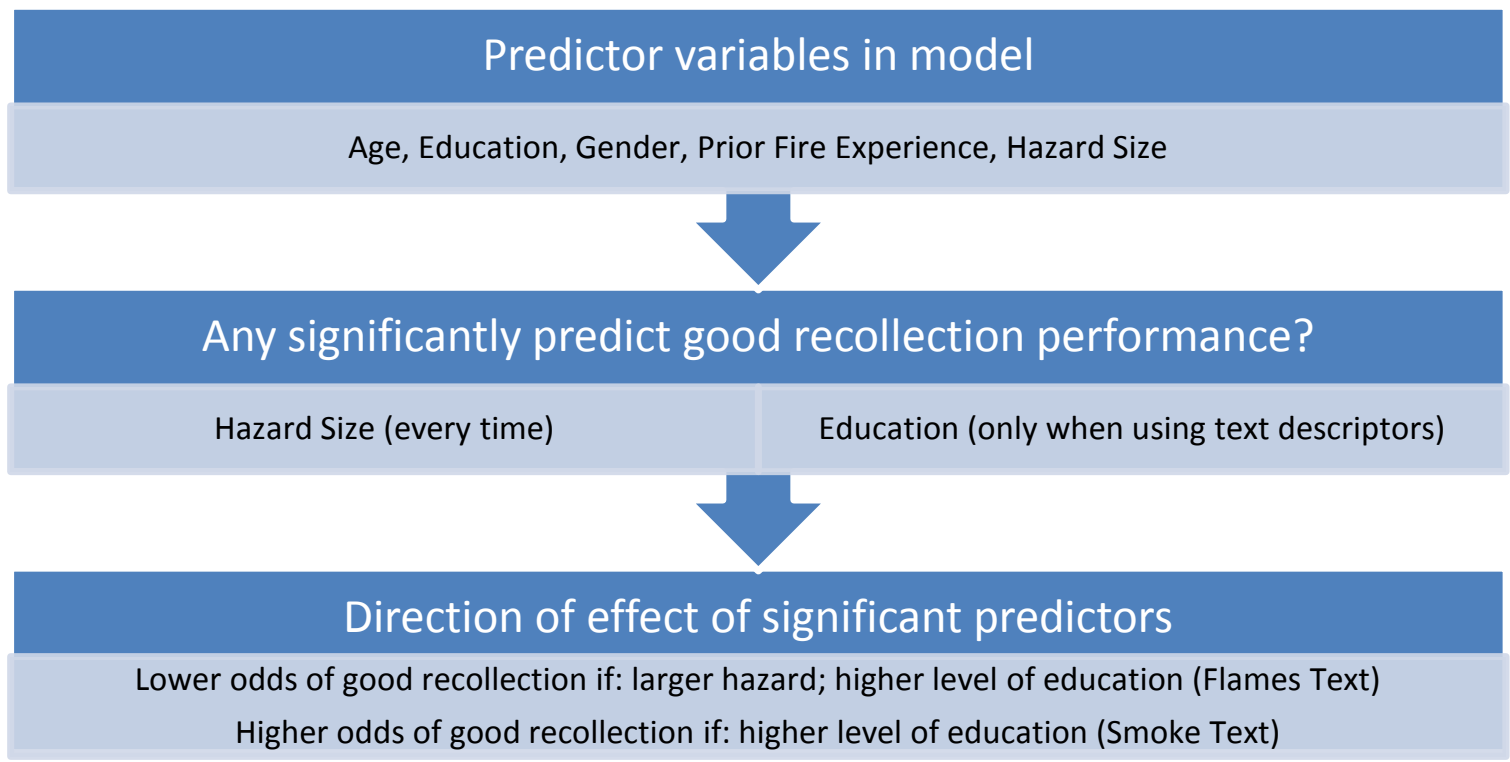

Fig.2. Summary of logistic regression results for predicting recollection performance (Exp. 1)

\subsection{Willingness to engage with fire hazards: effect of experimental manipulation}

Willingness was significantly negatively correlated with perceived hazard size (as expressed through the descriptors). That is, the taller the flames were (correctly or incorrectly) perceived to be, the less likely participants felt they could have safely extinguished them (Flame Text and Picture Descriptors, respectively: rho $=-.45$, rho $=-.46$, ps $<.001$ ). Likewise, the greater the perceived volume of smoke, the less willing participants were about entering the smoky room (Smoke Text and Picture Descriptors, respectively: rho $=-.58$, rho $=-.63$, ps $<.001$ ). Additionally, participants who were more likely to state they could have extinguished the flames were also significantly more likely to state they would have entered the smoky room (rho $=.37, p<.001$ ).

Willingness also seemed to be related to the actual size of the hazards. Overall, the most common answer was an affirmative one, that participants could have extinguished the flames $(52 \%)$ and would have entered the smoky room (44\%), with a further $23 \%$ and $19 \%$ answering Not Sure, 
and the remaining $25 \%$ and $37 \%$ answering No, respectively. However, hazard size appeared to affect willingness, with the frequency of Yes answers decreasing as hazard size increased (Extinguish Flames: Small $=81 \%$, Mid $=47 \%$, Large $=30 \%$; Enter Smoky Room: Small $=74 \%$, Mid $=42 \%$, Large $=$ 15\%), and the frequency of Not Sure answers increasing and then decreasing (Extinguish Flames: Small $=11 \%$, Mid $=36 \%$, Large $=23 \%$; Enter Smoky Room: Small $=19 \%$, Mid $=26 \%$, Large $=13 \%)$. Consequently, the frequency of No answers increased with increasing hazard size (Extinguish Flames: Small $=9 \%$, Mid $=17 \%$, Large $=47 \%$; Enter Smoky Room: Small $=6 \%$, Mid $=32 \%$, Large $=72 \%)$. It was noted that participants appeared more cautious towards smoke than flames.

\subsection{Willingness to engage with fire hazards: additional socio-demographic effects}

Logistic regression was employed again to test whether occupant characteristics, along with the experimental manipulation, significantly predicted the outcome of interest. However, this time the outcome was not binary but instead ordered (i.e. willingness ascending from a negative through to an affirmative answer - i.e. No, to Not Sure, to Yes). Thus, the specific type of test was ordinal logistic regression. Two tests were run, one for predicting willingness to attempt to extinguish the flames and one for predicting willingness to enter the room given the smoke present. As before, the predictor variables Age, Education, Gender, Prior Fire Experience and Hazard Size comprised a single block in the model. The interaction terms Age*Hazard Size, Education*Hazard Size, Gender*Hazard Size, and Prior Fire Experience*Hazard Size were then added and, on this occasion, their inclusion was found to significantly improve the model. Therefore, interactions are reported here.

Descriptive statistics and more detailed output from the logistic regression tests are available in Appendix C and D, respectively. A summary of the test results is shown here in Fig. 3. Hazard Size interacted with Gender to significantly predict willingness to engage with the fire hazards (Extinguish Flames - Female [vs. Male] ${ }^{*}$ Large [vs. Small]-sized hazard: $p=.005, \mathrm{OR}=0.06$; Enter Smoky Room - Female [vs. Male]*Mid/Large [vs. Small]-sized hazard: all ps $<.031$, all ORs $<$ 0.16). Hazard Size also interacted with Prior Fire Experience, but only to significantly predict 
willingness to engage with the flames (No [vs. Yes] Prior Fire Experience*Mid/Large [vs. Small]-sized hazard: all ps $<.039$, all ORs $<0.17$;). Prior Fire Experience did significantly predict willingness to engage with the smoke, but in this instance the effect was independent of the experimental manipulation (Enter Smoky Room - No [vs. Yes] Prior Fire Experience: $p=.049, \mathrm{OR}=4.11$ ).

\section{Predictor variables in model}

Age, Education, Gender, Prior Fire Experience, Hazard Size + interaction terms

\section{Any significantly predict willingness to engage?}

For flames, Gender (overridden by Gender*Hazard For smoke, Gender (overridden by Gender*Hazard Size), Prior Fire Experience*Hazard Size Size), Prior Fire Experience

\section{Direction of effect of significant predictors}

Lower odds of being willing if: female + larger flames or smoke; no prior fire experience + larger flames Higher odds of being willing if: no prior fire experience (regardless of size of smoke)

\section{Fig.3. Summary of logistic regression results for predicting willingness to engage (Exp. 1)}

\section{Discussion: Experiment 1}

The results highlight several key points to consider for the investigation of occupant perception and recollection of fire hazards in dwelling fires. First, simply asking occupants to freely recall what they encountered may not produce sufficient or specific detail, particularly regarding the size of the hazards, to make objective post-event judgements. Moreover, what details are freely recalled about hazard size may not necessarily be accurate. In this experiment, participants who both reported the size of the hazards and did so accurately were in the minority. However, the provision of layperson-friendly aids can assist recollection by an appreciable amount. Here, participants were provided first with text descriptors and then with picture descriptors that allowed 
hazard size to be recollected in relation to things that would always exist in indoor dwelling fire situations with persons present: i.e. the occupant and structural elements of the room. Participants were able to use parts of their body or the ceiling and walls as reference points, and it was observed that recollection performance was now around 2.5 times better.

Regarding the best type of descriptor to use, overall this study found recollection performance was only marginally better when using the picture as opposed to text descriptors. However, performance using the text descriptors did differ significantly according to the participants' level of education - an undesirable effect. Therefore, picture descriptors would seem more advantageous. A likely additional benefit (one not able to be tested here given the homogeneity of participants' ethnic groups) is that, unlike text which could suffer from language differences, pictures should be more universally understood.

Use of such descriptors can also assist objective post-event judgements about fire development and fire outcomes, as well as occupant behaviour. From the hazard sizes displayed, it is possible to gauge whether, at the point in time in question, the hazards had reached a particularly dangerous stage in their development. For example, flames reaching and spreading under the ceiling indicate a rapid escalation of the fire as fuel (in the ceiling) other than that in the seat of the fire becomes involved. Such fires have reached a stage of development that is beyond the capability of most untrained individuals to safely extinguish and so pose a particular risk of injury to occupants attempting such action. Similarly, a smoke layer that has descended to below head height will engulf standing occupants, resulting in obscuration, thereby making it difficult to see, and also inhalation of toxins and irritants, which could result in incapacitation and/or long-term health damage.

While the health of the people participating in the current study was not at risk, their recollection performance when encountering larger flames or a larger volume of smoke appeared to be. Results showed that accuracy was likely to be good when the hazard was smaller but somewhat impaired when larger. However, looking again at Table 3, it is clear that although the percentage of 
participants selecting the correct descriptor decreased as hazard size increased, those participants who were wrong did not usually over- or underestimate the size by a great margin. For example, the flame text descriptor most frequently (incorrectly) selected was $D$ - just one size lower than the correct text descriptor, E. In both cases, participants were reporting that the flames were at least as high as the ceiling; in other words, tall flames that would have reached above the head of any occupant. The incorrect option most frequently selected from the flame picture descriptors was C; again, this still describes tall flames (ones as tall as an adult). Indeed, it may be possible to say that this answer was also in fact correct, if one were to judge the absolute size of the flames from their base on the kitchen worktop, up the side of the wall, to their end point along the ceiling. Combining answers $\mathrm{C}$ and $\mathrm{E}$ would mean that almost three-quarters of participants who saw the large flames made "accurate" recollections about hazard size. Similarly, for the large volume of smoke, the incorrect text and picture descriptor most frequently chosen was $C$ which, again, was only one size below that of the correct option and also depicted a layer of smoke starting to descend from the ceiling while not wholly filling the room.

An exception to the above point was the answers about smoke in the Mid group; there, the text and picture descriptor most frequently selected overall was A, which lacked any mention or illustration of a smoke layer that was present at the ceiling and beginning to descend. Thus, one could conclude that participants in the Mid group were, on the whole, ignorant as to the true extent of the smoke in the room. A possible explanation may be that participants' attentional focus had narrowed in on the source of the threat, i.e. the item of ignition from where the hazard was being emitted, which was located in the lower-to-mid part of the room; thus, for the Small and Large groups, the smoke might have been better recollected because it was within that focus (either because it had not expanded much beyond it or because it had descended back into the line of vision) whereas, in the Mid group, the smoke layer at the ceiling would have been in the periphery and thus lacking attention (see, for example, Chapman and Underwood, 1998; Fawcett et al., 2013). Indeed, some comments made during the free recall test support the view that attentional 
narrowing occurred: e.g. "My eyes focused directly to the smoke", "My focus was drawn only to the fire and I have little clear recollection of other objects in the room".

Supporting findings from earlier studies - albeit ones not always simulating or examining domestic settings (Canter, 1996; Jin, 2002; Wood, 1972) - participants in this study displayed a willingness to engage with smoke and flames. Overall, only a quarter were definite about not thinking they could have safely extinguished the flames while just over a third were definite about not entering the smoky room. This suggests that people's immediate response to being faced with fire hazards in their own home may not tend to be one of inaction or withdrawal to a place of safety. Of course, participants were responding to a hypothetical scenario, they were not actually in a position to be able to take action towards the fires seen in the video clips, therefore there could be an element of "braggadocio" in answers. However, given the earlier research findings, indications are that some people are indeed willing to take risks around both types of fire hazard. In contrast to the work of Jin (2002), where participants were instructed to enter the smoky environment, this experiment offered movement into the smoke as a choice. Also in contrast to Jin's work, the motivation to move into the smoke here was not necessarily to reach an exit; a further look at the free recall test answers showed that only around a third of participants reported that there was a door in the room. Future studies should aim to quantify deliberate approach behaviours towards fire hazards during real dwelling fires, and examine associated motivations plus risks, e.g. of injury.

Willingness to engage with fire hazards might suggest that people fail to perceive the risk that such hazards pose to their safety. However, the moderating effect of hazard size revealed in the current study (i.e. willingness decreased as the perceived size of the hazard increased) indicates that participants undertook some evaluation of the danger and understood that, once a hazard had reached a certain level, it would be beyond the control of any layperson. Nevertheless, the fact that in the Large group there was still $53 \%$ and $28 \%$ of participants not definitely stating No to 
extinguishing the flames and entering the smoky room, respectively, suggests that, for some, there might not be a good appreciation of the level at which the threshold is situated.

Two alternative possible explanations for why people show willingness to engage with fire hazards is that they might appreciate the danger but (i) experience an overriding desire to achieve something that would inevitably involve approaching the fire (e.g. a wish to contain or extinguish the flames in order to prevent further property from being damaged; a need to pass through the smoke to open windows and reach fresh air), and/or (ii) be in denial that they could personally be at risk of injury - a state perhaps linked to an increased belief in one's ability to successfully control events. The finding that participants with no prior experience of fires were less willing to engage with the flames when they were larger suggests that experienced participants possessed an elevated belief that they could safely extinguish a larger fire. It might be that a successful interaction with flames previously bolstered their confidence. However, if the flames in the previous experience were smaller, that confidence could be misplaced. Interestingly, a lack of prior fire experience was associated with a greater willingness to engage with the smoke, irrespective of the volume, but it was also notable that participants on the whole appeared to display more caution towards the smoke, relative to the flames. While flames can be considered good in certain cases (e.g. heating, cooking), smoke is rarely if ever a sign of anything positive. People with prior fire experience might have a more pronounced sense of smoke representing something undesirable, especially given that the effects of smoke in a fire might be more widespread and linger longer.

Gender was also found to impact willingness. When the flames and smoke were up to the ceiling, females became less willing than males to engage with the hazards. It could be that fires, particularly those in a kitchen such as depicted here, with flames that are not taller than an adult or which are only producing puffs of smoke, may be perceived to be the responsibility of the person who regularly takes on the cooking role in the home. Females are more likely to have that role (Office for National Statistics, 2016). However, larger fires could be perceived to be more the 
responsibility of the person who regularly takes on the protector/defender role, which tends to be males (Lips, 2019). Additionally, a meta-analysis on risk-taking found that, across studies of hypothetical, self-reported and observed behaviour, males were more likely to take risks than females, and that gender differences were particularly evident in situations requiring physical skill and also situations where participants knew there was a risk of experiencing physical or psychological harm (Byrnes et al., 1999).

A second experiment was conducted to see if the findings from Experiment 1 could be replicated and to investigate more directly issues such as risk perception, risk-taking and a belief in one's ability to control events. There was a further aim: in real-life dwelling fires, occupants do not provide immediate recollections (e.g. it will take at least several minutes for fire crews to attend), and so Experiment 2 compared immediate vs. delayed recollection. Key details are now reported.

\section{Materials and Methods: Experiment 2}

\subsection{Participants}

Invites were sent this time by various electronic means of communication (e.g. organisational websites, Facebook pages, internal staff emails). A total of 287 survey links were clicked on, 136 surveys completed, and four excluded, again due to being completed after the deadline. Thus, the final sample was a total of 132 participants, with $57 \%$ male and $43 \%$ female. Ages ranged from 23 to 75 years old $(M=47.20$ years, $S D=12.78)$. Most participants $(86 \%)$ resided in the UK, $77 \%$ belonged to a White UK ethnic group, $19 \%$ were educated to secondary level, $36 \%$ to undergraduate level, and $45 \%$ to postgraduate level. All participants declared having gained fire safety knowledge from at least one source (typically the workplace, 61\%) and 60\% had prior fire experience. This time half of the sample worked in areas related to fire/fire safety and so a FireRelated Job variable was included in subsequent analyses. Visual impairments were again reported (61\%), but almost always (93\%) of a type that could be corrected with lenses.

\subsection{Design, materials and procedure}


In the mixed design, participants were again randomly and evenly assigned to one of three Hazard Size groups: Small $n=44$, Mid $n=44$, Large $n=44$. Half of the sample $(n=66)$ attempted to recollect the fire hazards immediately, as in Experiment 1, while half attempted recollection after a delay (c.15 minutes) during which they completed filler tasks. Recollection performance was again assessed using free recall, text and picture descriptors. In addition to socio-demographic characteristics, this experiment collected data on three further variables. Individual differences in risk-taking and risk perception were measured using the DOSPERT scale (Blais and Weber, 2006). Participants were first asked to rate how likely they would be to engage in risky activities or behaviours ( 30 items, five domains) if they were to find themselves in those situations. A 7-point scale was used, where $1=$ Extremely Unlikely and $7=$ Extremely Likely. Answers on the health/safety domain were summed, with higher scores representing greater risk-taking (possible score range $=6$ 42). Next, participants were asked to rate how risky they perceived each of the aforementioned activities/behaviours to be. Another 7-point rating scale was used, with $1=$ Not At All Risky and $7=$ Extremely Risky. Higher summed scores on the health/safety domain represented greater perceived risk (possible score range $=6-42$ ). Rotter's (1966) scale measured locus of control (LoC), presenting 29 pairs of opposing statements about everyday situations and asking participants to select the statement they agreed with most (either the one positing that the described outcome was determined by the subject's own actions or abilities [Internal LoC] or the one ascribing the outcome to forces such as the behaviour of others, luck, fate, etc. [External LoC]). Rotter's scoring procedure assigned one point to each External LoC statement selected for 23 out of the 29 pairs. Thus, a lower score indicated a stronger belief in being able to control events in one's life while a higher score indicated a stronger belief that what happens is typically outside one's own control (possible score range $=0-23)$. Median time to complete the experiment was 24 minutes $(I Q R=18-37)$ and eight minutes (IQR $=6-11)$ for the Delayed and Immediate Recollection conditions, respectively.

\section{Results: Experiment 2}




\subsection{Recollection performance}

As in Experiment 1, recollection performance using free recall was often poor and the frequency of good performance was improved when using descriptors to describe hazard size (Table 4). Performance on the two types of descriptor was again similar but the picture descriptors appeared to have a slight advantage.

Table 4. Frequency of good recollection performance, overall, across test methods and hazard

\begin{tabular}{lccc}
\hline Hazard & Free Recall & Text Descriptors & Picture Descriptors \\
\hline Flame Height & $35 \%$ & $61 \%$ & $66 \%$ \\
Smoke Volume & $19 \%$ & $49 \%$ & $55 \%$ \\
\hline
\end{tabular}

The results of the experimental manipulation on recollection performance (specifically accuracy) when using the descriptors were replicated. That is, for both types of descriptor, accuracy was greatest when the hazards were small and (a) decreased as flame height increased, while (b) decreased then increased somewhat as smoke volume increased (Table 5). Attempting to recollect the hazards after a delay did not alter this pattern of results. Additionally, binary logistic regression tests showed that Time of Recollection was not a significant predictor of accuracy (Flame Text Descriptor: $\mathrm{p}=.830, \mathrm{OR}=0.91$; Flame Picture Descriptor: $\mathrm{p}=.278$, OR $=0.62$; Smoke Text Descriptor: $p=.564, O R=1.25$; Smoke Picture Descriptor: $p=.557, O R=0.79$; nor was there any significant interaction between Time of Recollection and Hazard Size). 
Table 5. Flame and smoke descriptor selection according to hazard size and time of recollection (correct answer)

\begin{tabular}{|c|c|c|c|c|c|c|c|c|c|c|c|c|c|c|c|c|c|c|c|c|}
\hline & \multicolumn{10}{|c|}{ Immediate Recollection } & \multicolumn{10}{|c|}{ Delayed Recollection } \\
\hline & \multicolumn{5}{|c|}{ Text Descriptors } & \multicolumn{5}{|c|}{ Picture Descriptors } & \multicolumn{5}{|c|}{ Text Descriptors } & \multicolumn{5}{|c|}{ Picture Descriptors } \\
\hline & $A$ & B & $\mathrm{C}$ & $\mathrm{D}$ & $\mathrm{E}$ & $A$ & B & $\mathrm{C}$ & $\mathrm{D}$ & $E$ & $A$ & B & C & $\mathrm{D}$ & $E$ & A & B & C & $\mathrm{D}$ & $\mathrm{E}$ \\
\hline \multicolumn{21}{|c|}{ Flame } \\
\hline Small & $\underline{91 \%}$ & $9 \%$ & - & - & - & $\underline{95 \%}$ & - & $5 \%$ & - & - & $95 \%$ & - & - & $5 \%$ & - & $\underline{91 \%}$ & $5 \%$ & - & $5 \%$ & - \\
\hline Mid & $23 \%$ & $\underline{68 \%}$ & $5 \%$ & $5 \%$ & - & $18 \%$ & $\underline{77 \%}$ & $5 \%$ & - & - & $14 \%$ & $\underline{59 \%}$ & $18 \%$ & $9 \%$ & - & $14 \%$ & $\underline{68 \%}$ & $18 \%$ & - & - \\
\hline Large & - & - & $5 \%$ & $68 \%$ & $\underline{27 \%}$ & - & $5 \%$ & $50 \%$ & $9 \%$ & $\underline{36 \%}$ & - & $9 \%$ & $9 \%$ & $55 \%$ & $\underline{27 \%}$ & - & $9 \%$ & $36 \%$ & $27 \%$ & $\underline{27 \%}$ \\
\hline \multicolumn{21}{|c|}{ Smoke } \\
\hline Small & $\underline{73 \%}$ & $27 \%$ & - & - & - & 82\% & $18 \%$ & - & - & - & $\underline{77 \%}$ & $18 \%$ & - & - & $5 \%$ & $\underline{82 \%}$ & $14 \%$ & - & - & $5 \%$ \\
\hline Mid & $45 \%$ & $32 \%$ & $18 \%$ & $5 \%$ & - & $36 \%$ & $27 \%$ & $\underline{27 \%}$ & - & $9 \%$ & $18 \%$ & $55 \%$ & $27 \%$ & - & - & $27 \%$ & $45 \%$ & $27 \%$ & - & - \\
\hline Large & - & $9 \%$ & $23 \%$ & $\underline{50 \%}$ & $18 \%$ & - & $5 \%$ & $14 \%$ & $\underline{64 \%}$ & $18 \%$ & - & $5 \%$ & $41 \%$ & $\underline{50 \%}$ & $5 \%$ & - & $14 \%$ & $32 \%$ & $50 \%$ & $5 \%$ \\
\hline
\end{tabular}


Binary logistic regression tests (Fig. 4; moreover, see descriptive statistics in Appendix E) also showed that there was no additional effect of occupant socio-demographic characteristics on recollection of flames, irrespective of the type of descriptor used. That is, none of these variables were significant predictors of good recollection performance, only Hazard Size (Flame Text Descriptor - Mid [vs. Small]-sized hazard: $p=.001, \mathrm{OR}=0.10$; Large [vs. Small]-sized hazard: $p<.001$, $\mathrm{OR}=0.02$; Flame Picture Descriptor - Mid [vs. Small]-sized hazard: $p=.022, \mathrm{OR}=0.20$; Large [vs. Small]-sized hazard: $p<.001, \mathrm{OR}=0.03$; no significant interactions). However, for recollection of smoke, Hazard Size interacted significantly with Prior Fire Experience and Age, albeit only for the Mid group (Smoke Text Descriptor - No [vs. Yes] Prior Fire Experience*Mid [vs. Small]-sized smoke: p $=.014, \mathrm{OR}=0.02 ;$ Smoke Picture Descriptor - No [vs. Yes] Prior Fire Experience*Mid [vs. Small]-sized smoke: $p=.030, \mathrm{OR}=0.03 ;$ Age*Mid [vs. Small]-sized hazard: $\mathrm{p}=.042, \mathrm{OR}=0.86$ ).

\section{Predictor variables in model}

Age, Education, Gender, Prior Fire Experience, Fire-Related Job, Hazard Size (+ interaction terms for smoke)

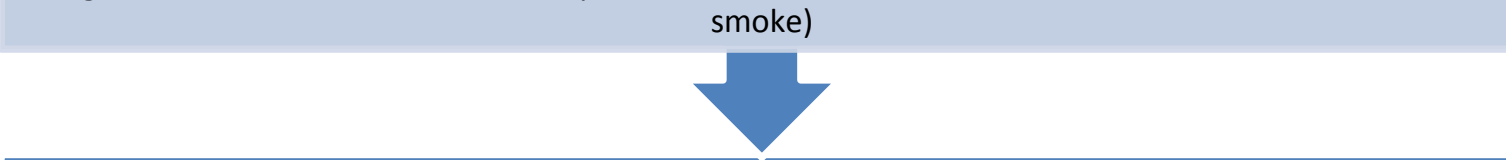

\section{Any significantly predict good recollection performance?}

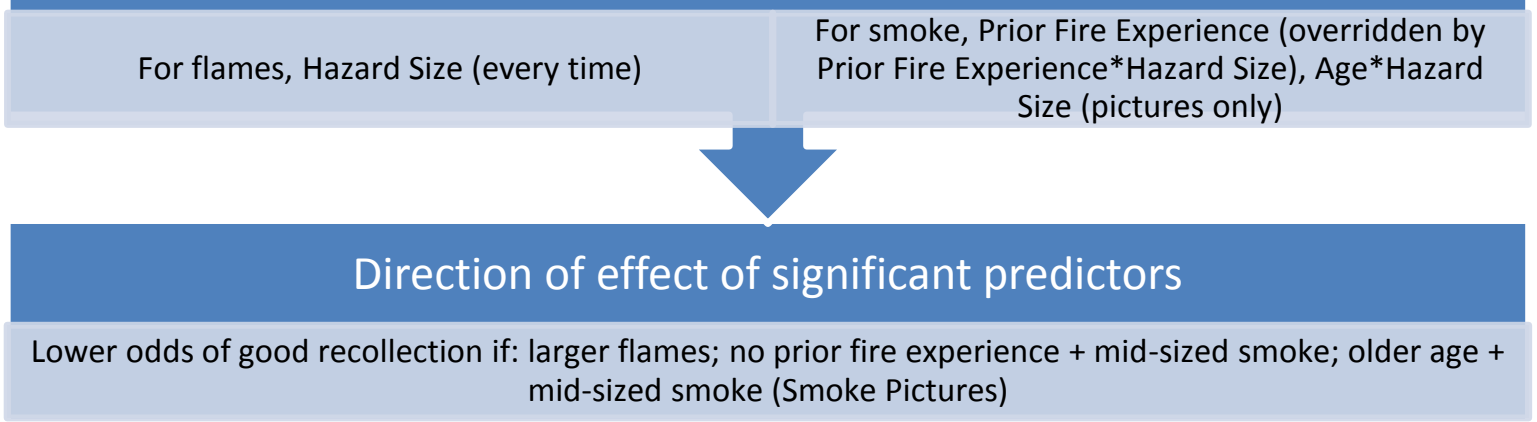

Fig.4. Summary of logistic regression results for predicting recollection performance (Exp. 2)

\subsection{Willingness to engage with fire hazards}


Again, willingness to engage with the flames and smoke was found to be significantly negatively correlated with the (correctly or not) perceived size of the hazards (Flame Text and Picture Descriptors, respectively: rho $=-.39$, rho $=-.40$, ps $<.001$; Smoke Text and Picture Descriptors, respectively: rho $=-.44$, rho $=-.48, \mathrm{ps}<.001)$. Willingness also appeared to be related to the actual size of the hazards: the frequency of Yes answers decreased as hazard size increased, while the frequency of Not Sure (NS) and No answers most often increased along with hazard size (Table 6). Ordinal logistic regression tests showed that Time of Recollection was not a significant predictor of willingness (Extinguish Flames: $p=.115$, OR $=0.54$; Enter Smoky Room: $p=.101, \mathrm{OR}=$ 0.54; nor was there any significant interaction between Time of Recollection and Hazard Size).

Table 6. Willingness to engage with hazards according to hazard size and time of recollection

\begin{tabular}{lccccccccccccc}
\hline & \multicolumn{4}{c}{ Immediate Recollection } & \multicolumn{4}{c}{ Delayed Recollection } \\
& \multicolumn{1}{c}{ Extinguish Flames } & \multicolumn{2}{c}{ Enter Smoky Room } & \multicolumn{3}{c}{ Extinguish Flames } & \multicolumn{2}{c}{ Enter Smoky Room } \\
& Yes & NS & No & Yes & NS & No & Yes & NS & No & Yes & NS & No \\
\hline Overall & $52 \%$ & $24 \%$ & $24 \%$ & $53 \%$ & $20 \%$ & $27 \%$ & $62 \%$ & $26 \%$ & $12 \%$ & $58 \%$ & $18 \%$ & $24 \%$ \\
Small & $77 \%$ & $14 \%$ & $9 \%$ & $82 \%$ & $9 \%$ & $9 \%$ & $82 \%$ & $14 \%$ & $5 \%$ & $77 \%$ & $14 \%$ & $9 \%$ \\
Mid & $50 \%$ & $27 \%$ & $23 \%$ & $59 \%$ & $18 \%$ & $23 \%$ & $59 \%$ & $23 \%$ & $18 \%$ & $55 \%$ & $14 \%$ & $32 \%$ \\
Large & $27 \%$ & $32 \%$ & $41 \%$ & $18 \%$ & $32 \%$ & $50 \%$ & $45 \%$ & $41 \%$ & $14 \%$ & $41 \%$ & $27 \%$ & $32 \%$ \\
\hline
\end{tabular}

Further ordinal logistic regression tests (Fig. 5; moreover, see descriptive statistics in Appendix F) found that occupant characteristics rarely affected willingness. For example, the new variable Fire-Related Job did not. Prior Fire Experience was the only socio-demographic variable to significantly predict willingness to engage with the flames (Extinguish Flames - No [vs. Yes] Prior Fire Experience: $p=.018, O R=0.51$ ). Hazard Size also significantly predicted willingness here (Extinguish Flames - Mid [vs. Small]-sized hazard: $p=.007, \mathrm{OR}=0.33$; Large [vs. Small]-sized hazard: $p<.001$, $\mathrm{OR}=0.17$; no significant interactions). For willingness to engage with the smoke, Hazard Size interacted significantly with Gender (Enter Smoky Room - Female [vs. Male]*Mid [vs. Small]-sized hazard: $p=.011, \mathrm{OR}=22.83$; Female [vs. Male] ${ }^{*}$ Large [vs. Small]-sized hazard: $\left.p=.016, \mathrm{OR}=17.48\right)$. 


\section{Predictor variables in model}

Age, Education, Gender, Prior Fire Experience, Fire-Related Job, Hazard Size (+ interaction terms for smoke)

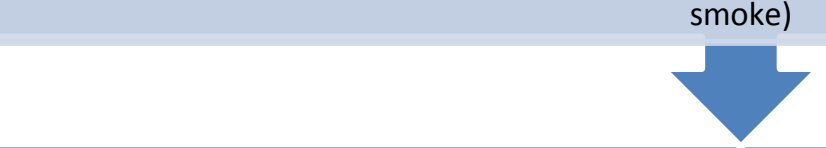

\section{Any significant predictors of willingness to engage?}

For flames, Prior Fire Experience, Hazard Size

For smoke, Gender (overridden by Gender*Hazard Size)

\section{Direction of effect of significant predictors}

Lower odds of being willing if: no prior fire experience (regardless of size of flames); larger flames Higher odds of being willing if: female + larger smoke

Fig.5. Summary of logistic regression results for predicting willingness to engage (Exp. 2)

\subsection{Individual differences in risk perception, risk-taking and LoC}

On the health/safety domain, the sample's mean risk perception score was $30.38(S D=6.34$, range of observed scores $=14-42 ;$ Cronbach's alpha $=.78$ ) and median risk-taking score was 16.50 $(I Q R=13.00-23.00$, range of observed scores $=6-32 ;$ Cronbach's alpha $=.70)$, while their mean LoC score was 11.50 (SD = 4.62, range of observed scores $=1-22$; Cronbach's alpha $=.70)$. Risk perception and risk-taking were significantly negatively correlated (rho $=-.59, p<.001$ ), i.e. the lower the perceived risk, the greater the risk-taking. LoC was negatively but not significantly correlated with both risk perception $(r=-.14, p=.280)$ and risk-taking ( $r h o=-.04, p=.764)$.

Participants who displayed good recollection for the flames and smoke tended to perceive greater risk in general than participants who displayed poor recollection, but a series of independent samples t-tests showed the difference was never significant; nor was there a significant relationship between believing in one's ability to control events and recollection of the hazards (Table 7). 
Table 7. Descriptive, inferential statistics: recollection performance, risk perception (RP) and LoC

\begin{tabular}{llcllllll}
\hline & \multicolumn{2}{c}{ Flame Text } & \multicolumn{2}{c}{ Smoke Text } & \multicolumn{2}{c}{ Flame Picture } & \multicolumn{2}{c}{ Smoke Picture } \\
& Good & Poor & Good & Poor & Good & Poor & Good & Poor \\
\hline Mean RP & 31.18 & 29.15 & 31.03 & 29.69 & 30.83 & 29.64 & 31.03 & 29.65 \\
(SD) & $(5.67)$ & $(7.19)$ & $(6.53)$ & $(6.15)$ & $(5.97)$ & $(6.97)$ & $(5.96)$ & $(6.76)$ \\
Test Results & $\mathrm{p}=.208, \mathrm{~d}=0.31$ & $\mathrm{p}=.394, \mathrm{~d}=0.21$ & $\mathrm{p}=.464, \mathrm{~d}=0.18$ & $\mathrm{p}=.380, \mathrm{~d}=0.22$ \\
Mean LoC & 11.13 & 12.08 & 12.09 & 10.88 & 11.22 & 11.96 & 11.91 & 11.03 \\
(SD) & $(4.93)$ & $(4.11)$ & $(4.98)$ & $(4.19)$ & $(4.49)$ & $(4.87)$ & $(5.15)$ & $(3.95)$ \\
Test Results & $\mathrm{p}=.417, \mathrm{~d}=0.21$ & \multicolumn{2}{c}{$\mathrm{p}=.289, \mathrm{~d}=0.26$} & $\mathrm{p}=.531, \mathrm{~d}=0.16$ & $\mathrm{p}=.443, \mathrm{~d}=0.19$ \\
\hline
\end{tabular}

Furthermore, a series of independent samples t-tests (for risk perception and LoC) and Mann-Whitney $U$ tests (for risk-taking) revealed at least one of the socio-demographic predictors of willingness observed in Experiments 1 and 2 (Gender) was significantly related to some individual differences variables - i.e. compared to males, females were less likely to take risks in general and less likely to believe they can control events. However, correlation tests showed that there were no direct significant relationships between risk perception, risk-taking or LoC and willingness to engage with the hazards (Table 8).

Table 8. Descriptive, inferential statistics: willingness, risk perception (RP), risk-taking (RT) and LoC

\begin{tabular}{|c|c|c|c|c|c|c|}
\hline & \multicolumn{2}{|c|}{ Gender } & \multicolumn{2}{|c|}{ Prior Fire Experience } & \multirow[t]{2}{*}{ Extinguish Flames } & \multirow[t]{2}{*}{ Enter Smoky Room } \\
\hline & Male & Female & Yes & No & & \\
\hline Mean RP & 29.56 & 31.56 & 29.49 & 31.39 & - & - \\
\hline (SD) & $(6.02)$ & $(6.71)$ & $(6.61)$ & $(5.97)$ & - & - \\
\hline Test Results & \multicolumn{2}{|c|}{$p=.212, d=0.31$} & \multicolumn{2}{|c|}{$p=.227, d=0.30$} & rho $=.11, p=.381$ & rho $=.17, p=.186$ \\
\hline Median RT & 17.00 & 14.00 & 17.00 & 15.00 & - & - \\
\hline (IQR) & $(15-25)$ & $(12-17)$ & $(14-25)$ & $(13-20)$ & - & - \\
\hline Test Results & \multicolumn{2}{|c|}{$p=.007, r=-.33$} & \multicolumn{2}{|c|}{$p=.089, r=-.21$} & rho $=.11, p=.397$ & rho $=.03, p=.818$ \\
\hline Mean LoC & 10.41 & 13.07 & 12.00 & 10.94 & - & - \\
\hline (SD) & $(4.38)$ & $(4.57)$ & $(5.17)$ & (3.91) & - & - \\
\hline Test Results & \multicolumn{2}{|c|}{$p=.020, d=0.59$} & \multicolumn{2}{|c|}{$p=.354, d=0.23$} & rho $=-.16, p=.194$ & rho $=.01, p=.955$ \\
\hline
\end{tabular}




\section{Discussion: Experiment 2}

The results of Experiment 1 were largely replicated. Hazard size was not well recollected when left to free recall but recollection performance was around 2-3 times better when using descriptors. As before, performance was marginally better when using the picture as opposed to text descriptors.

The experimental manipulation of hazard size once more affected recollection performance, with accuracy getting progressively worse as the height of the flames increased and accuracy decreasing then improving somewhat as the volume of smoke increased. This time, the effect of Hazard Size on recollection performance for smoke volume interacted with some socio-demographic variables (Age, Prior Fire Experience) for participants in the Mid group. The possibility of attentional narrowing occurring, as discussed in section 4, could also account for these additional findings: studies of ageing have concluded that older adults compensate for perceptual deficits by narrowing attention towards central vision, at a cost to seeing things in the periphery (Power and Conlon, 2017), while driving studies have shown that inexperienced drivers display greater attentional focusing than experienced drivers in dangerous situations, likely due to lacking relevant hazard knowledge and therefore not being able to process and move onto other details as quickly (Chapman and Underwood, 1998).

Recollection performance was not linked to individual differences in perceiving health/safety risks in general, nor to beliefs in one's ability to control events, which suggests that not all kinds of self-evaluation contribute to distorted perception of hazardous situations (cf. self-esteem and perception of height when unable to protect oneself in Harber et al., 2011). Moreover, neither recollection performance nor willingness to engage with the fire hazards were significantly affected by a time delay. This gives confidence that in real-life dwelling fires, where statements may not be taken from occupants immediately, recollections of the hazards encountered and occupant behaviour or intentions towards those hazards might be preserved, at least over a short time. 
Overall, participants who were definite about not engaging with the fire hazards were in the minority. However, as before, willingness to engage was tempered by the perceived and actual size of the hazard, reinforcing the notion that some risk assessment occurs. Nonetheless, the sight of large hazards certainly did not deter participants completely: it was notable that when the hazards were depicted at their worst height/volume, a considerable percentage of participants - even larger than that observed in Experiment 1 - felt sure or at least appeared to be entertaining the possibility that they could safely extinguish the flames (Yes and Not Sure answers combined: $59 \%-86 \%$ ) or would enter the smoky room (Yes and Not Sure answers combined: 50\%-68\%). These figures are concerning. Even if the percentage willing in real dwelling fires was found to be lower, it would still likely mean that a sizeable number of occupants put themselves in danger. Thus, the findings definitely argue for greater research into occupant behaviours and injury outcomes.

Gender and Prior Fire Experience were again found to significantly predict willingness, although the results were not entirely consistent with those in Experiment 1 . While males and females still differed in their willingness, this was now only for engaging with the smoke and the effect was in the opposite direction, i.e. females were more willing when the volume of smoke was larger. This was surprising; not only is it contrary to the findings from Experiment 1 and the wider literature on gender differences discussed therein, but also females in the current sample were found to be significantly less likely to take risks in health/safety scenarios and believe they can control events. However, the lack of a significant direct relationship between either risk-taking or LoC and willingness suggests that such individual differences are not the factors underlying the gender effects on engaging with fire hazards. Nor were the females in this sample simply less perceptive in general of risks to their health/safety than the males. Household roles were discussed in section 4 and it may be that fewer males and females in Experiment 2 observed these traditional roles in their homes, either due to living alone, being single parents, or in same-sex relationships, thereby cancelling out or reversing some outcomes. Clearly more research is required on gender 
differences in dwelling fire responses and future studies should probe whether other occupant/household characteristics underlie them.

Consistent with Experiment 1, non-experienced participants were less willing to engage with the flames, but this was now the case across all groups, and there was no difference for the smoke. As discussed in section 4, Prior Fire Experience effects might be dependent on the outcomes of the earlier experiences. While the current experiment's findings now suggest prior experiences with successful outcomes might not be linked to a greater belief in one's ability to control events in general, they might nevertheless be linked to beliefs about controlling fires. In future, it would useful to collect more information about prior experiences, e.g. whether they too involved a small or larger fire, whether flames or smoke were more prominent, whether the fire was easily controlled, and whether the occupant became injured through engaging with it. It is worth noting that Experiment 2 was able to test for effects of being in a fire-related job and no significant results were detected. Thus, it would seem that personal rather than professional experience is more key.

\section{Conclusions}

These two experiments demonstrate that it may be possible for people experiencing dwelling fires to recollect, even after a delay, hazard properties such as the size of flames and smoke when first encountered and their behavioural responses to that. However, an important finding from this work is that the recollection of hazard size is likely to be more forthcoming and meaningful when people are provided with tools to help them, and the investigators, visualise the hazards in relation to other elements of the scene, i.e. the occupant's body and the built environment. Larger hazards may result in less accurate recollections, in terms of precision due to attentional narrowing potentially, but may still be relatively meaningful (if describing flames at least).

Larger hazards may also deter behaviours that would bring the occupant into closer proximity with them and thus more danger. So risks posed by hazard size do appear to be perceived, 
to an extent. However, it is also important to be aware that, based on the findings here, the number of occupants deterred by larger hazards may be relatively small and the results on this matter raise concern. It would appear that certain factors - linked to occupant characteristics such as gender and prior personal experience of a fire but not individual differences in risk-taking and locus of control will lead some people to nevertheless attempt to tackle flames of a height beyond the control of an untrained individual or enter a room containing sufficient smoke to impair one's functioning and health. Such behaviours in turn may explain, or at least contribute to, the incidence of dwelling fire injuries. Thus, if non-fatal injury outcomes are to be better understood and the number of such injuries reduced, the links between hazard size, occupant behaviour, occupant characteristics, and the likelihood of being injured need to be researched further in domestic settings.

\section{References}

Blais, A.R., Weber, E.U., 2006. A domain-specific risk-taking (DOSPERT) scale for adult populations. Judgment and Decision Making 1, 33-47.

Brennan, P., 1999. Victims and survivors in fatal residential building fires. Fire and Materials 23, 305310.

Byrnes, J.P., Miller, D.C., Schafer, W.D., 1999. Gender differences in risk-taking: a meta-analysis. Psychological Bulletin 125, 367-383.

Canter, D.V., 1996. An overview of behaviour in fires. In: Canter, D.V. (Ed.), Psychology in Action, pp. 159-188. Dartmouth Publishing Co, Aldershot, England.

Chapman, P.R., Underwood, G., 1998. Visual search of driving situations: danger and experience. Perception 27, 951-964.

DiGuiseppi, C., Edwards, P., Godward, C., Roberts, I., Wade, A., 2000. Urban residential fire and flame injuries: a population based study. Injury Prevention 6, 250-254. 
Fawcett, J.M., Russell, E.J., Peace, K.A., Christie, J. 2013. Of guns and geese: A meta-analytic review of the 'weapon focus' literature. Psychology, Crime and Law 19, 35-66.

Haikonen, K., Lillsunde, P.M., Lunetta, P., Lounamaa, A., Vuola, J., 2013. Fire-related injuries with inpatient care in Finland: a 10-year nationwide study. Burns 39, 796-802.

Hall Jr., J.R., 2004. How many people can be saved from home fires if given more time to escape? Fire Technology 40, 117-126.

Harber, K.D., Yeung, D., lacovelli, A., 2011. Psychosocial resources, threat, and the perception of distance and height: Support for the Resources and Perception Model. Emotion 11, 10801090.

Harpur, A., Boyce, K., McConnell, N., 2014. An investigation into the circumstances surrounding elderly dwelling fire fatalities and the barriers to implementing fire safety strategies among this group. Fire Safety Science 11, 1144-1159.

Hasofer, A.M., Thomas, I., 2006. Analysis of fatalities and injuries in building fire statistics. Fire Safety Journal 41, 2-14.

Holborn, P.G., Nolan, P.F., Golt, J., 2003. An analysis of fatal unintentional dwelling fires investigated by London Fire Brigade between 1996 and 2000. Fire Safety Journal 38, 1-42.

Home Office, 2018. Detailed Analysis of Fires Attended by Fire and Rescue Services, England, April 2017 to March 2018. Home Office, London, England.

Ialongo, C., 2016. Understanding the effect size and its measures. Biochemia Medica 26, 150-163.

Jin, T., 2002. Visibility and human behavior in fire smoke. In: Beyler, C.L. (Section 2 Ed.), SFPE Handbook of Fire Protection Engineering ( ${ }^{\text {rd }}$ Edition), pp. 2-42-2-53. National Fire Protection Association, Quincy, MA. 
Kobes, M., Groenewegen, K., 2009. Consumer Fire Safety: European Statistics and Potential Fire Safety Measures. Netherlands Institute for Safety Nibra, Arnhem, Netherlands.

Lips, H.M., 2019. Gender: The Basics (2 ${ }^{\text {nd }}$ Edition). Routledge, Abingdon, England.

Lollar, K., 2010. The liminal experience: loss of extended self after the fire. Qualitative Inquiry 16, $262-270$.

Miller, I., 2005. Human Behaviour Contributing to Unintentional Residential Fire Deaths 1997-2003 (Research Report No.47). New Zealand Fire Service Commission, Wellington, New Zealand.

Office for National Statistics, 2016. Women Shoulder the Responsibility of 'Unpaid Work'. https://www.ons.gov.uk/employmentandlabourmarket/peopleinwork/earningsandworkingh ours/articles/womenshouldertheresponsibilityofunpaidwork/2016-11-10 (Mar. 11, 2019)

Power, G.F., Conlon, E.G., 2017.Perceptual processing deficits underlying reduced FFOV efficiency in older adults. Journal of Vision 17, 1-11.

Rotter, J.B., 1966. Generalized expectancies for internal versus external control of reinforcement. Psychological Monographs: General and Applied 80, 1-28.

Runyan, C.W., Bangdiwala, S.I., Linzer, M.A., Sacks, J.J., Butts, J., 1992. Risk factors for fatal residential fires. The New England Journal of Medicine 327, 859-863.

Safer, M.A., Christianson, S-Å., Autry, M.W., Österlund, K., 1998. Tunnel memory for traumatic events. Applied Cognitive Psychology 12, 99-117.

Scottish Fire and Rescue Service, 2018. Fire and Rescue Incident Statistics (Scotland) 2017-18. Scottish Fire and Rescue Service, Cambuslang, Scotland.

Thompson, O.F., Wales, D., 2015. A qualitative study of experiences, actions and motivations during accidental dwelling fires. Fire and Materials 39, 453-465. 
U.S. Fire Administration, 2019. U.S. fire statistics. https://www.usfa.fema.gov/data/statistics/ (Mar. $11,2019)$

Wales, D.G., Thompson, O.F., Hulse, L.M., Galea, E.R., 2015. From data to difference - considering the application of a large-scale database of human behaviour in accidental dwelling fires. In: Proceedings of the $6^{\text {th }}$ International Symposium on Human Behaviour in Fire 2015, pp. 465476. Interscience Communications, London, England.

Warda, L., Tenenbein, M., Moffatt, M.E.K., 1999. House fire injury prevention update Part I: a review of risk factors for fatal and non-fatal house fire injury. Injury Prevention 5, 145-150.

Wood, P.G., 1972. The Behaviour of People in Fires (Fire Research Note No.953). Fire Research Station, Borehamwood, England. 
Appendix A. Descriptive statistics: good recollection performance according to socio-demographic characteristics and type of descriptor (Experiment 1)

\begin{tabular}{|c|c|c|c|c|c|c|c|c|c|c|c|c|c|c|c|c|}
\hline \multirow[b]{2}{*}{ Characteristics } & \multicolumn{4}{|c|}{ Flame Text } & \multicolumn{4}{|c|}{ Smoke Text } & \multicolumn{4}{|c|}{ Flame Picture } & \multicolumn{4}{|c|}{ Smoke Picture } \\
\hline & overall & Small & Mid & Large & overall & Small & Mid & Large & overall & Small & Mid & Large & overall & Small & Mid & Large \\
\hline \multicolumn{17}{|l|}{ Mean Age } \\
\hline - Good Perf. & $59 \mathrm{yr}$ & $58 \mathrm{yr}$ & $59 \mathrm{yr}$ & $61 \mathrm{yr}$ & $58 \mathrm{yr}$ & $57 \mathrm{yr}$ & $57 \mathrm{yr}$ & $61 \mathrm{yr}$ & $61 \mathrm{yr}$ & $59 \mathrm{yr}$ & $61 \mathrm{yr}$ & $65 \mathrm{yr}$ & $60 \mathrm{yr}$ & $58 \mathrm{yr}$ & $59 \mathrm{yr}$ & $65 \mathrm{yr}$ \\
\hline - Poor Perf. & $62 \mathrm{yr}$ & $56 \mathrm{yr}$ & $63 \mathrm{yr}$ & $63 \mathrm{yr}$ & $62 \mathrm{yr}$ & $62 \mathrm{yr}$ & $61 \mathrm{yr}$ & $63 \mathrm{yr}$ & $58 \mathrm{yr}$ & $53 \mathrm{yr}$ & $57 \mathrm{yr}$ & $60 \mathrm{yr}$ & $60 \mathrm{yr}$ & $57 \mathrm{yr}$ & $60 \mathrm{yr}$ & $61 \mathrm{yr}$ \\
\hline \multicolumn{17}{|l|}{ Education } \\
\hline - Secondary & $72 \%$ & $94 \%$ & $84 \%$ & $48 \%$ & $36 \%$ & $69 \%$ & $11 \%$ & $35 \%$ & $69 \%$ & $81 \%$ & $89 \%$ & $43 \%$ & $43 \%$ & $75 \%$ & $16 \%$ & $43 \%$ \\
\hline - Undergrad & $60 \%$ & $79 \%$ & $70 \%$ & $24 \%$ & $35 \%$ & $64 \%$ & $20 \%$ & $29 \%$ & $67 \%$ & $93 \%$ & $75 \%$ & $35 \%$ & $39 \%$ & $71 \%$ & $15 \%$ & $41 \%$ \\
\hline - Postgrad & $66 \%$ & $88 \%$ & $63 \%$ & $14 \%$ & $72 \%$ & $94 \%$ & $25 \%$ & $71 \%$ & $72 \%$ & $82 \%$ & $63 \%$ & $57 \%$ & $63 \%$ & $94 \%$ & $25 \%$ & $29 \%$ \\
\hline \multicolumn{17}{|l|}{ Gender } \\
\hline - Male & $58 \%$ & $85 \%$ & $68 \%$ & $34 \%$ & $40 \%$ & $75 \%$ & $12 \%$ & $41 \%$ & $70 \%$ & $95 \%$ & $80 \%$ & $47 \%$ & $44 \%$ & $80 \%$ & $20 \%$ & $41 \%$ \\
\hline - Female & $73 \%$ & $89 \%$ & $82 \%$ & $33 \%$ & $48 \%$ & $78 \%$ & $23 \%$ & $33 \%$ & $67 \%$ & $78 \%$ & $77 \%$ & $33 \%$ & $48 \%$ & $81 \%$ & $14 \%$ & $40 \%$ \\
\hline \multicolumn{17}{|l|}{ Prior Fire Exp. } \\
\hline - Yes & $61 \%$ & $83 \%$ & $68 \%$ & $36 \%$ & $42 \%$ & $75 \%$ & $9 \%$ & $39 \%$ & $62 \%$ & $83 \%$ & $73 \%$ & $36 \%$ & $46 \%$ & $79 \%$ & $9 \%$ & $46 \%$ \\
\hline$-N o$ & $70 \%$ & $91 \%$ & $80 \%$ & $32 \%$ & $46 \%$ & $78 \%$ & $24 \%$ & $37 \%$ & $76 \%$ & $87 \%$ & $84 \%$ & $53 \%$ & $46 \%$ & $83 \%$ & $24 \%$ & $32 \%$ \\
\hline
\end{tabular}


Appendix B. Binary logistic regression output: predicting good recollection performance (Experiment 1)

\begin{tabular}{|c|c|c|c|c|c|c|c|c|}
\hline \multirow[b]{2}{*}{ Variable } & \multicolumn{2}{|c|}{ Flame Text } & \multicolumn{2}{|c|}{ Smoke Text } & \multicolumn{2}{|c|}{ Flame Picture } & \multicolumn{2}{|c|}{ Smoke Picture } \\
\hline & OR & $95 \% \mathrm{Cl}$ & OR & $95 \% \mathrm{Cl}$ & OR & $95 \% \mathrm{Cl}$ & OR & $95 \% \mathrm{Cl}$ \\
\hline Age & 0.99 & $0.96-1.03$ & 0.98 & $0.94-1.01$ & 1.03 & $0.99-1.06$ & 1.01 & $0.98-1.05$ \\
\hline \multicolumn{9}{|l|}{ Education } \\
\hline - Undergraduate (vs. Secondary) & $0.34^{+}$ & $0.13-0.90$ & 1.08 & $0.44-2.65$ & 0.84 & $0.33-2.13$ & 0.88 & $0.36-2.17$ \\
\hline - Postgraduate (vs. Secondary) & 0.33 & $0.10-1.06$ & $4.40^{++}$ & $1.43-13.51$ & 0.67 & $0.23-2.01$ & 1.57 & $0.54-4.51$ \\
\hline Gender - Female (vs. Male) & 1.20 & $0.48-2.98$ & 1.03 & $0.43-2.49$ & 0.56 & $0.22-1.43$ & 1.00 & $0.42-2.40$ \\
\hline Prior Fire Experience. - No (vs. Yes) & 1.15 & $0.50-2.65$ & 1.23 & $0.55-2.79$ & 2.17 & $0.93-5.07$ & 1.07 & $0.48-2.39$ \\
\hline \multicolumn{9}{|l|}{ Hazard Size } \\
\hline - Mid (vs. Small) & 0.40 & $0.13-1.23$ & $0.07^{+++}$ & $0.02-0.19$ & 0.51 & $0.16-1.59$ & $0.05^{+++}$ & $0.02-0.15$ \\
\hline - Large (vs. Small) & $0.06^{+++}$ & $0.02-0.19$ & $0.25^{++}$ & $0.10-0.64$ & $0.08^{+++}$ & $0.03-0.26$ & $0.17^{+++}$ & $0.06-0.44$ \\
\hline
\end{tabular}

Note: Reference categories for categorical predictor variables are shown in parentheses, i.e. "(vs. ...)"; OR = odds ratio; $\mathrm{Cl}=$ confidence interval for the odds ratio; ${ }^{+} p<.05,{ }^{++} p<.01,{ }^{+++} p<$

$.001 ;$ Flame Text Model $X^{2}(7)=39.85, p<.001 ;\left(\right.$ Nagelkerke) $R^{2}=.34 ;$ overall prediction success $=75 \% ;$ Smoke Text Model $X^{2}(7)=47.73, p<.001 ; R^{2}=.38$, overall prediction success $=75 \%$;

Flame Picture Model $X^{2}(7)=31.21, p<.001 ; R^{2}=.28$, overall prediction success $=75 \%$; Smoke Picture Model $X^{2}(7)=44.01, p<.001 ; R^{2}=.36$, overall prediction success $=74 \%$. 
Appendix C. Descriptive statistics: willingness to engage with hazards according to socio-demographic characteristics (Experiment 1)

\begin{tabular}{|c|c|c|c|c|c|c|c|c|c|c|c|c|c|c|c|c|c|}
\hline & & \multicolumn{8}{|c|}{ Extinguish Flames } & \multicolumn{8}{|c|}{ Enter Smoky Room } \\
\hline & & \multirow[t]{2}{*}{ Age } & \multicolumn{3}{|c|}{ Education } & \multicolumn{2}{|c|}{ Gender } & \multicolumn{2}{|c|}{ Prior Exp. } & \multirow[t]{2}{*}{ Age } & \multicolumn{3}{|c|}{ Education } & \multicolumn{2}{|c|}{ Gender } & \multicolumn{2}{|c|}{ Prior Exp. } \\
\hline & & & $S$ & $U$ & $P$ & $M$ & $F$ & $Y$ & $N$ & & $S$ & $U$ & $P$ & $M$ & $F$ & $Y$ & $N$ \\
\hline \multirow[t]{3}{*}{ Overall } & Yes & & $53 \%$ & $43 \%$ & $66 \%$ & $49 \%$ & $56 \%$ & $58 \%$ & $46 \%$ & & $41 \%$ & $39 \%$ & $56 \%$ & $39 \%$ & $50 \%$ & $35 \%$ & $54 \%$ \\
\hline & Not Sure & -.01 & $19 \%$ & $29 \%$ & $22 \%$ & $29 \%$ & $17 \%$ & $20 \%$ & $27 \%$ & -.05 & $14 \%$ & $25 \%$ & $19 \%$ & $21 \%$ & $17 \%$ & $22 \%$ & $16 \%$ \\
\hline & No & & $28 \%$ & $27 \%$ & $13 \%$ & $22 \%$ & $27 \%$ & $22 \%$ & $27 \%$ & & $45 \%$ & $35 \%$ & $25 \%$ & $40 \%$ & $33 \%$ & $43 \%$ & $30 \%$ \\
\hline \multirow[t]{3}{*}{ Small } & Yes & & $88 \%$ & $71 \%$ & $82 \%$ & $65 \%$ & $93 \%$ & $75 \%$ & $87 \%$ & & $75 \%$ & $71 \%$ & $76 \%$ & $60 \%$ & $85 \%$ & $63 \%$ & $87 \%$ \\
\hline & Not Sure & $\zeta-.03$ & $0 \%$ & $21 \%$ & $12 \%$ & $20 \%$ & $4 \%$ & $13 \%$ & $9 \%$ & --.36 & $13 \%$ & $21 \%$ & $24 \%$ & $30 \%$ & $11 \%$ & $25 \%$ & $13 \%$ \\
\hline & No & & $13 \%$ & $7 \%$ & $6 \%$ & $15 \%$ & $4 \%$ & $13 \%$ & $4 \%$ & & $13 \%$ & $7 \%$ & $0 \%$ & $10 \%$ & $4 \%$ & $13 \%$ & $0 \%$ \\
\hline \multirow[t]{3}{*}{ Mid } & Yes & & $53 \%$ & $40 \%$ & $50 \%$ & $56 \%$ & $36 \%$ & $64 \%$ & $32 \%$ & & $42 \%$ & $40 \%$ & $50 \%$ & $48 \%$ & $36 \%$ & $36 \%$ & $48 \%$ \\
\hline & Not Sure & \}.18 & $37 \%$ & $40 \%$ & $25 \%$ & $32 \%$ & $41 \%$ & $23 \%$ & $48 \%$ & -.17 & $26 \%$ & $30 \%$ & $13 \%$ & $24 \%$ & $27 \%$ & $27 \%$ & $24 \%$ \\
\hline & No & & $11 \%$ & $20 \%$ & $25 \%$ & $12 \%$ & $23 \%$ & $14 \%$ & $20 \%$ & & $32 \%$ & $30 \%$ & $38 \%$ & $28 \%$ & $36 \%$ & $36 \%$ & $28 \%$ \\
\hline \multirow[t]{3}{*}{ Large } & Yes & & $30 \%$ & $24 \%$ & $43 \%$ & $34 \%$ & $20 \%$ & $39 \%$ & $16 \%$ & & $17 \%$ & $12 \%$ & $14 \%$ & $19 \%$ & $7 \%$ & $11 \%$ & $21 \%$ \\
\hline & Not Sure & \}.07 & $17 \%$ & $24 \%$ & $43 \%$ & $31 \%$ & $7 \%$ & $25 \%$ & $21 \%$ & 女.19 & $4 \%$ & $24 \%$ & $14 \%$ & $13 \%$ & $13 \%$ & $14 \%$ & $11 \%$ \\
\hline & No & & $52 \%$ & $53 \%$ & $14 \%$ & $34 \%$ & $73 \%$ & $36 \%$ & $63 \%$ & & $78 \%$ & $65 \%$ & $71 \%$ & $69 \%$ & $80 \%$ & $75 \%$ & $68 \%$ \\
\hline
\end{tabular}

Note: $S=$ Secondary, $U=$ Undergraduate, $P=$ Postgraduate; $M=$ Male, $F=$ Female; $Y=Y e s, N=$ No; for the continuous variable Age, the values in the columns are Spearman's rho correlation

coefficients representing the strength of the association between Age (in years) and willingness ratings, while for the categorical variables, Education, Gender and Prior Fire Experience, the values in the columns represent the percentage of participants who provided the answer Yes/Not Sure/No. 
Appendix D. Ordinal logistic regression output: predicting willingness to engage (Experiment 1)

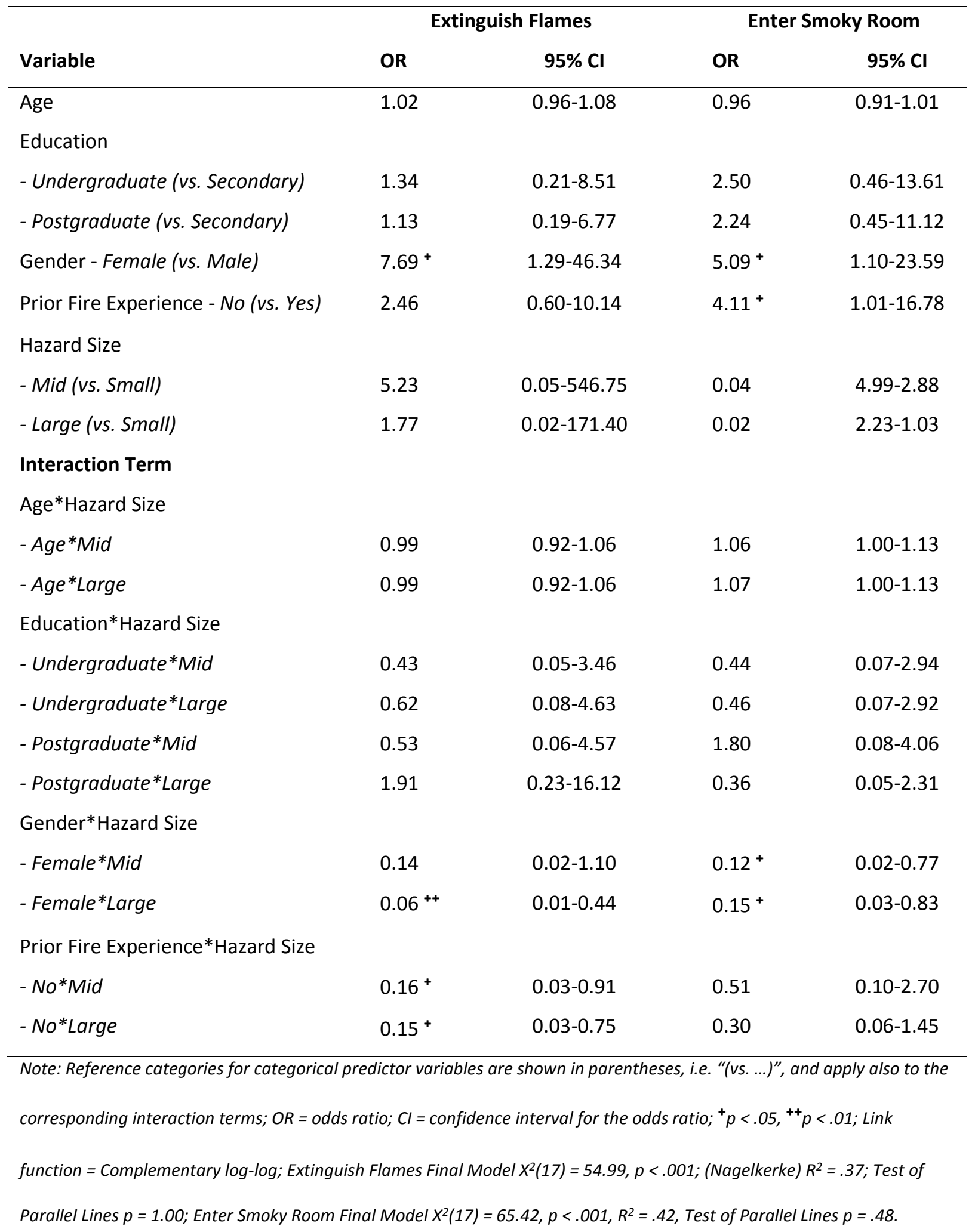


Appendix E. Descriptive statistics: good recollection performance according to socio-demographic characteristics and type of descriptor (Experiment 2)

\begin{tabular}{|c|c|c|c|c|c|c|c|c|c|c|c|c|c|c|c|c|}
\hline \multirow[b]{2}{*}{ Characteristics } & \multicolumn{4}{|c|}{ Flame Text } & \multicolumn{4}{|c|}{ Smoke Text } & \multicolumn{4}{|c|}{ Flame Picture } & \multicolumn{4}{|c|}{ Smoke Picture } \\
\hline & overall & Small & Mid & Large & overall & Small & Mid & Large & overall & Small & Mid & Large & overall & Small & Mid & Large \\
\hline \multicolumn{17}{|l|}{ Mean Age } \\
\hline - Good Perf. & $47 \mathrm{yr}$ & $46 \mathrm{yr}$ & $47 \mathrm{yr}$ & $48 \mathrm{yr}$ & $46 \mathrm{yr}$ & $47 \mathrm{yr}$ & $47 \mathrm{yr}$ & $46 \mathrm{yr}$ & $47 \mathrm{yr}$ & $47 \mathrm{yr}$ & $45 \mathrm{yr}$ & $51 \mathrm{yr}$ & $47 \mathrm{yr}$ & $48 \mathrm{yr}$ & $47 \mathrm{yr}$ & $45 \mathrm{yr}$ \\
\hline - Poor Perf. & $48 \mathrm{yr}$ & $46 \mathrm{yr}$ & $49 \mathrm{yr}$ & $48 \mathrm{yr}$ & $48 \mathrm{yr}$ & $43 \mathrm{yr}$ & $48 \mathrm{yr}$ & $50 \mathrm{yr}$ & $48 \mathrm{yr}$ & $35 \mathrm{yr}$ & $54 \mathrm{yr}$ & $47 \mathrm{yr}$ & $48 \mathrm{yr}$ & $37 \mathrm{yr}$ & $48 \mathrm{yr}$ & $52 \mathrm{yr}$ \\
\hline \multicolumn{17}{|l|}{ Education } \\
\hline - Secondary & $68 \%$ & $88 \%$ & $60 \%$ & $57 \%$ & $44 \%$ & $75 \%$ & $30 \%$ & $29 \%$ & $72 \%$ & $100 \%$ & $70 \%$ & $43 \%$ & $44 \%$ & $88 \%$ & $30 \%$ & $14 \%$ \\
\hline - Undergrad & $58 \%$ & $94 \%$ & $60 \%$ & $19 \%$ & $52 \%$ & $65 \%$ & $33 \%$ & $56 \%$ & $63 \%$ & $94 \%$ & $80 \%$ & $13 \%$ & $60 \%$ & $71 \%$ & $40 \%$ & $69 \%$ \\
\hline - Postgrad & $61 \%$ & $95 \%$ & $68 \%$ & $24 \%$ & $49 \%$ & $84 \%$ & $11 \%$ & $52 \%$ & $66 \%$ & $89 \%$ & $68 \%$ & $43 \%$ & $56 \%$ & $89 \%$ & $16 \%$ & $62 \%$ \\
\hline \multicolumn{17}{|l|}{ Gender } \\
\hline - Male & $68 \%$ & $96 \%$ & $70 \%$ & $40 \%$ & $44 \%$ & $74 \%$ & $19 \%$ & $44 \%$ & $67 \%$ & $91 \%$ & $74 \%$ & $36 \%$ & $52 \%$ & $87 \%$ & $22 \%$ & $52 \%$ \\
\hline - Female & $53 \%$ & $90 \%$ & $53 \%$ & $11 \%$ & $56 \%$ & $76 \%$ & $29 \%$ & $58 \%$ & $65 \%$ & $95 \%$ & $71 \%$ & $26 \%$ & $60 \%$ & $76 \%$ & $35 \%$ & $63 \%$ \\
\hline \multicolumn{17}{|l|}{ Prior Fire Exp. } \\
\hline - Yes & $61 \%$ & $96 \%$ & $63 \%$ & $29 \%$ & $42 \%$ & $58 \%$ & $26 \%$ & $43 \%$ & $61 \%$ & $92 \%$ & $70 \%$ & $25 \%$ & $52 \%$ & $71 \%$ & $30 \%$ & $57 \%$ \\
\hline$-N o$ & $62 \%$ & $90 \%$ & $65 \%$ & $25 \%$ & $60 \%$ & $95 \%$ & $18 \%$ & $63 \%$ & $74 \%$ & $95 \%$ & $76 \%$ & $44 \%$ & $60 \%$ & $95 \%$ & $24 \%$ & $56 \%$ \\
\hline \multicolumn{17}{|l|}{ Fire-Related Job } \\
\hline - Yes & $65 \%$ & $95 \%$ & $70 \%$ & $33 \%$ & $50 \%$ & $68 \%$ & $15 \%$ & $63 \%$ & $68 \%$ & $91 \%$ & $85 \%$ & $33 \%$ & $59 \%$ & $82 \%$ & $20 \%$ & $71 \%$ \\
\hline$-N o$ & $58 \%$ & $91 \%$ & $58 \%$ & $20 \%$ & $48 \%$ & $82 \%$ & $29 \%$ & $35 \%$ & $64 \%$ & $95 \%$ & $63 \%$ & $30 \%$ & $52 \%$ & $82 \%$ & $33 \%$ & $40 \%$ \\
\hline
\end{tabular}




\section{Appendix F. Descriptive statistics: willingness to engage with hazards according to socio-demographic characteristics (Experiment 2)}

\begin{tabular}{|c|c|c|c|c|c|c|c|c|c|c|c|c|c|c|c|c|c|c|c|c|c|}
\hline & & \multicolumn{10}{|c|}{ Extinguish Flames } & \multicolumn{10}{|c|}{ Enter Smoky Room } \\
\hline & & \multirow[t]{2}{*}{ Age } & \multicolumn{3}{|c|}{ Education } & \multicolumn{2}{|c|}{ Gender } & \multicolumn{2}{|c|}{ Prior Exp. } & \multicolumn{2}{|c|}{ Fire Job } & \multirow[t]{2}{*}{ Age } & \multicolumn{3}{|c|}{ Education } & \multicolumn{2}{|c|}{ Gender } & \multicolumn{2}{|c|}{ Prior Exp. } & \multicolumn{2}{|c|}{ Fire Job } \\
\hline & & & $S$ & $U$ & $P$ & $M$ & $F$ & $Y$ & $N$ & $Y$ & $N$ & & $S$ & $U$ & $P$ & $M$ & $F$ & $Y$ & $N$ & $Y$ & $N$ \\
\hline \multirow[t]{3}{*}{ Overall } & Yes & & $48 \%$ & $63 \%$ & $56 \%$ & $64 \%$ & $47 \%$ & $65 \%$ & $45 \%$ & $62 \%$ & $52 \%$ & & $56 \%$ & $58 \%$ & $53 \%$ & $59 \%$ & $51 \%$ & $56 \%$ & $55 \%$ & $55 \%$ & $56 \%$ \\
\hline & NS & -.08 & $16 \%$ & $23 \%$ & $31 \%$ & $23 \%$ & $28 \%$ & $22 \%$ & $30 \%$ & $23 \%$ & $27 \%$ & .08 & $16 \%$ & $17 \%$ & $22 \%$ & $17 \%$ & $21 \%$ & $20 \%$ & $17 \%$ & $20 \%$ & $18 \%$ \\
\hline & No & & $36 \%$ & $15 \%$ & $14 \%$ & $13 \%$ & $25 \%$ & $14 \%$ & $25 \%$ & $15 \%$ & $21 \%$ & & $28 \%$ & $25 \%$ & $25 \%$ & $24 \%$ & $28 \%$ & $24 \%$ & $28 \%$ & $26 \%$ & $26 \%$ \\
\hline \multirow[t]{3}{*}{ Small } & Yes & & $75 \%$ & $82 \%$ & $79 \%$ & $83 \%$ & $76 \%$ & $83 \%$ & $75 \%$ & $77 \%$ & $82 \%$ & & $88 \%$ & $82 \%$ & $74 \%$ & $96 \%$ & $62 \%$ & $79 \%$ & $80 \%$ & $77 \%$ & $82 \%$ \\
\hline & NS & \}.11 & $13 \%$ & $12 \%$ & $16 \%$ & $13 \%$ & $14 \%$ & $8 \%$ & $20 \%$ & $18 \%$ & $9 \%$ & t.14 & $13 \%$ & $6 \%$ & $16 \%$ & $4 \%$ & $19 \%$ & $8 \%$ & $15 \%$ & $18 \%$ & $5 \%$ \\
\hline & No & & $13 \%$ & $6 \%$ & $5 \%$ & $4 \%$ & $10 \%$ & $8 \%$ & $5 \%$ & $5 \%$ & $9 \%$ & \rfloor & $0 \%$ & $12 \%$ & $11 \%$ & $0 \%$ & $19 \%$ & $13 \%$ & $5 \%$ & $5 \%$ & $14 \%$ \\
\hline \multirow[t]{3}{*}{ Mid } & Yes & & $50 \%$ & $60 \%$ & $53 \%$ & $67 \%$ & $35 \%$ & $63 \%$ & $41 \%$ & $60 \%$ & $50 \%$ & & $60 \%$ & $53 \%$ & $58 \%$ & $56 \%$ & $59 \%$ & $56 \%$ & $59 \%$ & $60 \%$ & $54 \%$ \\
\hline & NS & $\zeta .06$ & $20 \%$ & $20 \%$ & $32 \%$ & $19 \%$ & $35 \%$ & $22 \%$ & $29 \%$ & $20 \%$ & $29 \%$ & L.03 & $10 \%$ & $13 \%$ & $21 \%$ & $15 \%$ & $18 \%$ & $19 \%$ & $12 \%$ & $15 \%$ & $17 \%$ \\
\hline & No & & $30 \%$ & $20 \%$ & $16 \%$ & $15 \%$ & $29 \%$ & $15 \%$ & $29 \%$ & $20 \%$ & $21 \%$ & & $30 \%$ & $33 \%$ & $21 \%$ & $30 \%$ & $24 \%$ & $26 \%$ & $29 \%$ & $25 \%$ & $29 \%$ \\
\hline \multirow[t]{3}{*}{ Large } & Yes & & $14 \%$ & $44 \%$ & $38 \%$ & $44 \%$ & $26 \%$ & $50 \%$ & $13 \%$ & $50 \%$ & $20 \%$ & & $14 \%$ & $38 \%$ & $29 \%$ & $28 \%$ & $32 \%$ & $36 \%$ & $19 \%$ & $29 \%$ & $30 \%$ \\
\hline & $N S$ & $\zeta-.32$ & $14 \%$ & $38 \%$ & $43 \%$ & $36 \%$ & $37 \%$ & $32 \%$ & $44 \%$ & $29 \%$ & $45 \%$ & \}.16 & $29 \%$ & $31 \%$ & $29 \%$ & $32 \%$ & $26 \%$ & $32 \%$ & $25 \%$ & $25 \%$ & $35 \%$ \\
\hline & No & & $71 \%$ & $19 \%$ & $19 \%$ & $20 \%$ & $37 \%$ & $18 \%$ & $44 \%$ & $21 \%$ & $35 \%$ & \rfloor & $57 \%$ & $31 \%$ & $43 \%$ & $40 \%$ & $42 \%$ & $32 \%$ & $56 \%$ & $46 \%$ & $35 \%$ \\
\hline
\end{tabular}

Note: $S=$ Secondary, $U=$ Undergraduate, $P=$ Postgraduate; $M=$ Male, $F=$ Female; $Y=Y e s, N=$ No, NS = Not Sure; for the continuous variable Age, the values in the columns are Spearman's

rho correlation coefficients representing the strength of the association between Age (in years) and willingness ratings, while for the categorical variables, Education, Gender, Prior Fire

Experience and Fire-Related Job, the values in the columns represent the percentage of participants who provided the answer Yes/Not Sure/No. 